\title{
Paving the Way for the Lignin Hydrogenolysis Mechanism by Deuterium-Incorporated $\beta-0-4$ Mimics
}

\author{
Helong Li and Guoyong Song*
}

Beijing Advanced Innovation Center for Tree Breeding by Molecular Design, Beijing Key Laboratory of Lignocellulosic Chemistry, Beijing Forestry University, No.35 Tsinghua East Road, Beijing 100083, China.

E-mail: songg@bjfu.edu.cn

\section{Table of Contents}

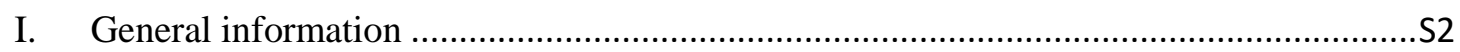

II. Reported pathways of lignin hydrogenolysis with late transition metal catalysts............S3

III. Preparation of deuterated $\beta-O-4$ lignin polymer LP-D ..............................................S4

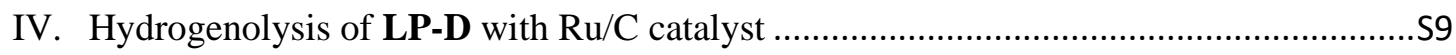

V. Hydrogenolysis of deuterium-incorporated $\beta-\mathrm{O}-4$ mimics with $\mathrm{Pd} / \mathrm{C}$ catalyst ...............S11

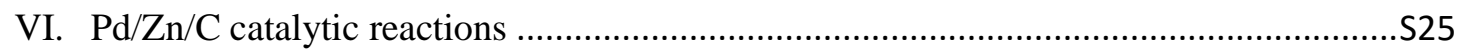

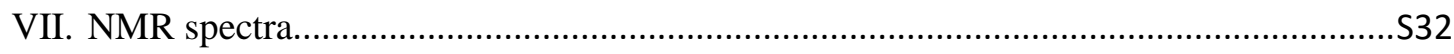

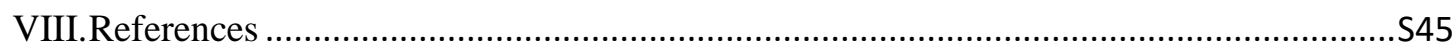




\section{General information}

All commercially available chemical reagents were used without further purification unless especially noted. $\mathrm{Ru} / \mathrm{C}(\mathrm{Ru}$ content: $5 \mathrm{wt} \%)$ and $\mathrm{Pd} / \mathrm{C}(\mathrm{Pd}$ content: $5 \mathrm{wt} \%)$ were purchased from Energy Chemical. Deuterium-incorporated dimeric lignin model compounds VG-D and GG-D were prepared following previously reported procedures. ${ }^{1}$

GPC analyses were performed on a Shimadzu LC-20A instrument equipped with a refraction index detector on a PL-gel $10 \mu \mathrm{m}$ Mixed-B $7.5 \mathrm{~mm}$ ID column, calibrated with polystyrene standards (peaks average molecular weights of 96, 500, 1,320, 9,200, 66,000 g/mol for macromolecule). For artificial lignin polymer: the dry polymer was dissolved in THF ( $\left.2 \mathrm{mg} \mathrm{mL}^{-1}\right)$ and filtered with a PTFE filter $(0.45 \mu \mathrm{m})$, which was then submitted for analysis.

GC and GC-MS analyses were carried out on a Shimadzu Model 2010 plus equipped with a HP5 column $(30 \mathrm{~m} \times 0.25 \mathrm{~mm} \times 0.25 \mathrm{~mm})$ using a flame ionization detector (FID) and a Shimadzu GCMS-QP2010SE equipped with a HP-5MS $(30 \mathrm{~m} \times 0.25 \mathrm{~mm} \times 0.25 \mathrm{~mm})$ column, respectively. The injection temperature was $250{ }^{\circ} \mathrm{C}$. The column temperature program was: $50^{\circ} \mathrm{C}(3 \mathrm{~min}), 8^{\circ} \mathrm{C}$ $\min ^{-1}$ to $280^{\circ} \mathrm{C}$ (5 min). The detection temperature was $200^{\circ} \mathrm{C}$ for FID.

NMR spectra $\left({ }^{1} \mathrm{H}\right.$ and $\left.{ }^{13} \mathrm{C}\right)$ were acquired on a Bruker AVIII $400 \mathrm{MHz}$ spectrometer at $25{ }^{\circ} \mathrm{C}$. Samples were dissolved in DMSO- $d_{6}$ (synthetic lignin polymer) or $\mathrm{CDCl}_{3}$ (depolymerized products). As for ${ }^{1} \mathrm{H}$ NMR data are reported as follows: chemical shift in ppm $(\delta)$, multiplicity ( $\mathrm{s}=$ singlet, $\mathrm{d}$ $=$ doublet, $\mathrm{t}=$ triplet, $\mathrm{m}=$ multiplet, $\mathrm{br}=$ broad $)$, coupling constant $(\mathrm{Hz})$, and integration .

Powder X-ray diffraction (XRD) patterns of samples were recorded on an Ultima IV operating at $40 \mathrm{kV}$ voltage and $15 \mathrm{~mA}$ current with $\mathrm{Cu} \mathrm{K} \alpha$ radiation $(\lambda=0.15406 \mathrm{~nm})$. Samples were scanned from $10^{\circ}$ to $80^{\circ}(2 \theta)$ at a speed of $2^{\circ} / \mathrm{min}$. Transmission electron microscopy (TEM) was carried out by a JEOL JEM 2100F equipped with energy dispersive X-ray spectrometer (EDX) analysis at 100 $\mathrm{kV}$, and the EDX elemental mapping were operated at $200 \mathrm{kV}$. X-ray photoelectron spectroscopy (XPS) was collected on scanning X-ray microprobe (Escalab 250Xi) using Al Ka radiation and the C1s peak at $284.6 \mathrm{eV}$ as internal standard.

Catalytic hydrogenolysis reactions were carried out in $50 \mathrm{~mL}$ autoclave with a magnetic stirring bar in $\mathrm{MeOH}$. The catalyst dosages were $5 \mathrm{wt} \%$ for dimetric models and $10 \mathrm{wt} \%$ for polymetric models in this manuscript if without any specific note. 


\section{Reported pathways of lignin hydrogenolysis with late transition metal catalysts}

$$
\begin{aligned}
& \mathrm{C}_{\alpha} \text {-ketone pathways }{ }^{1-3} \\
& \begin{array}{ccc}
\text { Cu20-PMO } & \text { Lignin }
\end{array} \\
& \text { A } \\
& \stackrel{\text { Pd/C }}{\longrightarrow}
\end{aligned}
$$

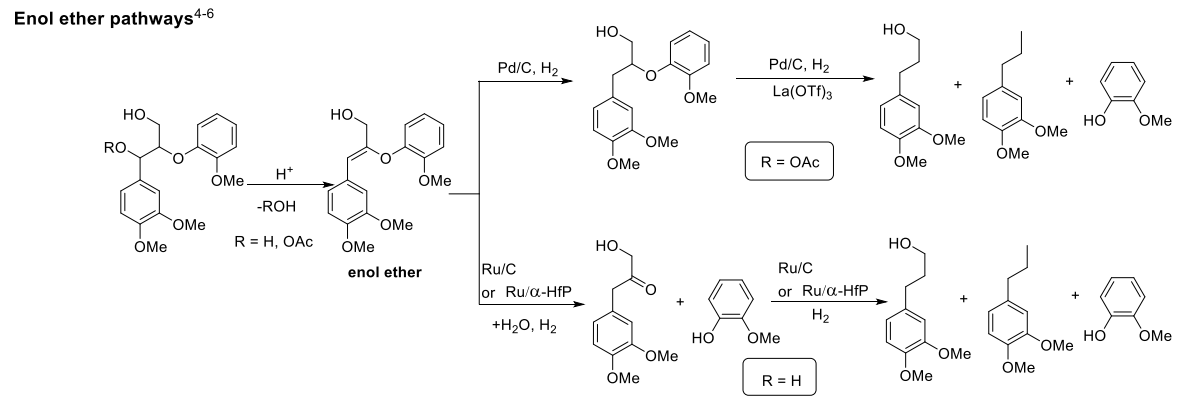

Hydrogenolysis of $\mathrm{C}_{\beta}-\mathrm{O}$ pathways $\mathrm{s}^{7-9}$
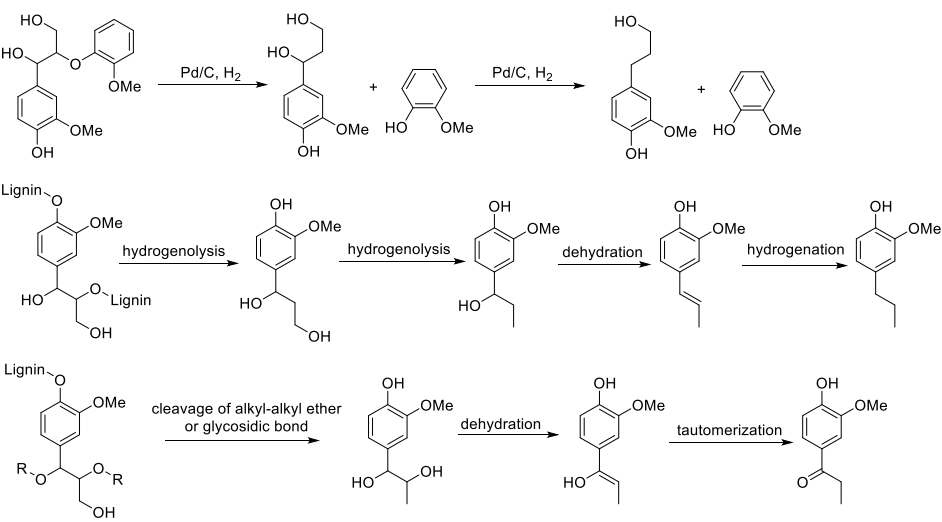

Radical pathways ${ }^{10,11}$

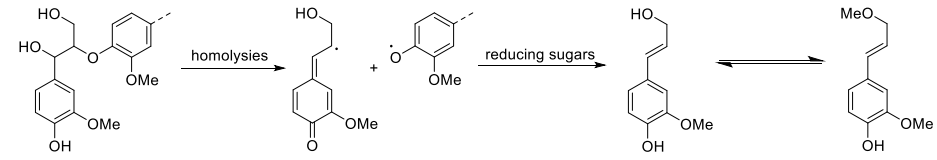

Concerted pathways ${ }^{12}$

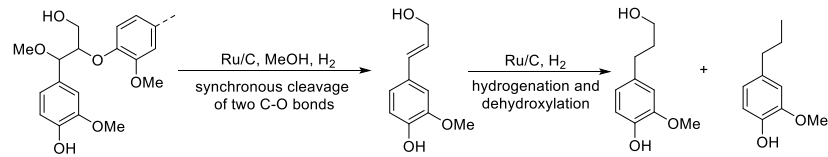

Figure S1. Reported pathways for lignin and model compounds hydrogenolysis with late transition metal catalysts ${ }^{1-12}$ 


\section{Preparation of deuterated $\beta$-O-4 lignin polymer LP-D}

The synthesis of $\mathbf{L P}-\boldsymbol{D}$

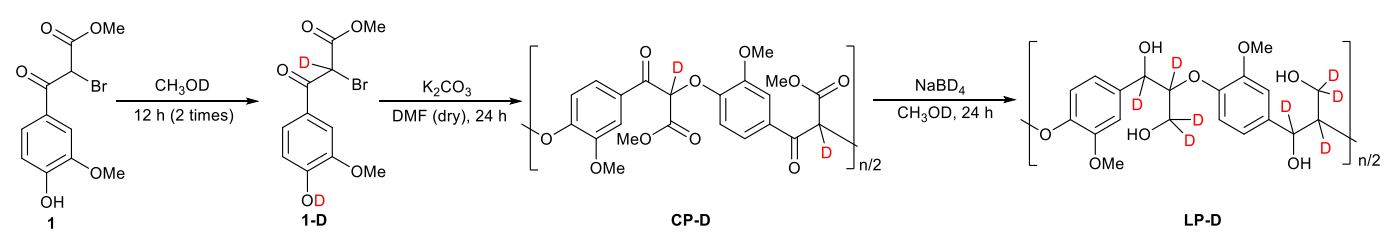

Methyl 2-bromo-3-(4-(hydroxy-D)-3-methoxyphenyl)-3-oxopropanoate-2-D (1-D).

In glovebox, compound $1(5 \mathrm{~g}, 16.5 \mathrm{mmol})$ was dissolved in $\mathrm{CH}_{3} \mathrm{OD}(10 \mathrm{~mL})$ under room temperature. After $12 \mathrm{~h}$ stirring, the solvent was evaporated under vacuo and the residue was treated with fresh $\mathrm{CH}_{3} \mathrm{OD}$ again. The removal of $\mathrm{CH}_{3} \mathrm{OD}$ gave a solid product as 1-D quantitatively, which was stored under $\mathrm{N}_{2}$ and was used for next procedure directly. ${ }^{1} \mathbf{H}$ NMR $\left(400 \mathrm{MHz}, \mathrm{CDCl}_{3}\right): \delta 7.60$ $-7.58(\mathrm{~m}, 2 \mathrm{H}), 6.99(\mathrm{~d}, J=8.8 \mathrm{~Hz}, 1 \mathrm{H}), 3.98(\mathrm{~s}, 3 \mathrm{H}), 3.85(\mathrm{~s}, 3 \mathrm{H}) .{ }^{13} \mathbf{C} \mathbf{N M R}\left(100 \mathrm{MHz}, \mathrm{CDCl}_{3}\right)$ : $186.6,165.9,151.5,146.9,126.0,124.7,114.1,110.0,56.2,53.9,45.3(\mathrm{~d}, J=22.5 \mathrm{~Hz})$.

\section{Carbonyl polymer (CP-D)}

Anhydrous $\mathrm{K}_{2} \mathrm{CO}_{3}(1.36 \mathrm{~g}, 9.84 \mathrm{mmol})$ was added to the solution of compound 1-D (2 g, 6.56 mmol) in anhydrous DMF $(10 \mathrm{~mL})$ portion-wisely, and light brown mixture was formed. The reaction mixture was stirred under nitrogen at room temperature for $24 \mathrm{~h}$ in dark. After reaction, the reaction mixture was poured into $\mathrm{D}_{2} \mathrm{O}(50 \mathrm{~mL})$, then adjusted to $\mathrm{pH}=2$ by using concentrated $\mathrm{DCl} / \mathrm{D}_{2} \mathrm{O}$ solution to precipitate the polymer. After freezing overnight, the precipitate was isolated through centrifuging, and CP-D was obtained as a white solid after freeze-drying (1.4 g, 95\%). ${ }^{1} \mathrm{H}$ NMR (400 MHz, DMF- $\left.d_{7}\right) \delta: 7.70-7.58$ (m, 2H, ArH), 7.11 (br, 1H, ArH), 3.76 (br, 3H, OMe), 3.71 (br, 3H, OMe). The signal for $\beta-\mathrm{H}$ was not observed in CP-D.

Note: CP-D should be stored under $\mathrm{N}_{2}$ because $\beta$-D is readily replaced with an acidic proton.

\section{Deuterated Lignin Polymer (LP-D)}

To a stirred suspension of CP-D $(1 \mathrm{~g})$ in $\mathrm{CH}_{3} \mathrm{OD}(15 \mathrm{~mL})$ was added $\mathrm{NaBD}_{4}(1.3 \mathrm{~g})$ portionwisely at $0{ }^{\circ} \mathrm{C}$ and the mixture gradually became to clear. After stirring at room temperature for 24 
$\mathrm{h}$, the reaction mixture was quenched with saturated $\mathrm{NH}_{4} \mathrm{Cl}$ aqueous solution. The reaction mixture was poured into water $(80 \mathrm{~mL})$, then adjusted to $\mathrm{pH}=2$ by using concentrated $\mathrm{HCl}$ to precipitate the polymer. The resulted precipitate was isolated by centrifuge, washed with water and then dissolved in 1,2-dichloroethane-ethanol $(2: 1, \mathrm{v} / \mathrm{v}, 20 \mathrm{~mL})$. The resulting solution was poured into diethyl ether $(100 \mathrm{~mL})$ to remove low molecular weight compounds. The precipitate was filtered and then dried with freeze-drying to give LP-D $(0.38 \mathrm{~g}, 43 \%) .{ }^{1} \mathrm{H}$ NMR (400 MHz, DMSO- $\left.d_{6}\right) \delta$ : $7.05-6.84$ (m, 3H, ArH), 5.34 (br, 1H, OH), 4.63 (br, 1H, OH), 3.71 (br, 3H, OMe). ${ }^{13} \mathbf{C}$ NMR (100 MHz, DMSO- $\left.d_{6}\right): \delta 149.5,147.3,135.5,119.6,115.5,112.1,83.4,71.4,59.5,55.9$. The side chain signals in non-deuterium $\beta-\mathrm{O}-4$ polymer ( $\mathbf{L P})$ corresponding to $\mathrm{C}_{\alpha}-\mathrm{H}$ (br, $4.76 \mathrm{ppm}$ ), $\mathrm{C}_{\beta}-\mathrm{H}$ (br, 4.30 ppm) and $\mathrm{C}_{\gamma}-\mathrm{H}_{2}(3.52,3.60 \mathrm{ppm})$ could not be found in LP-D.

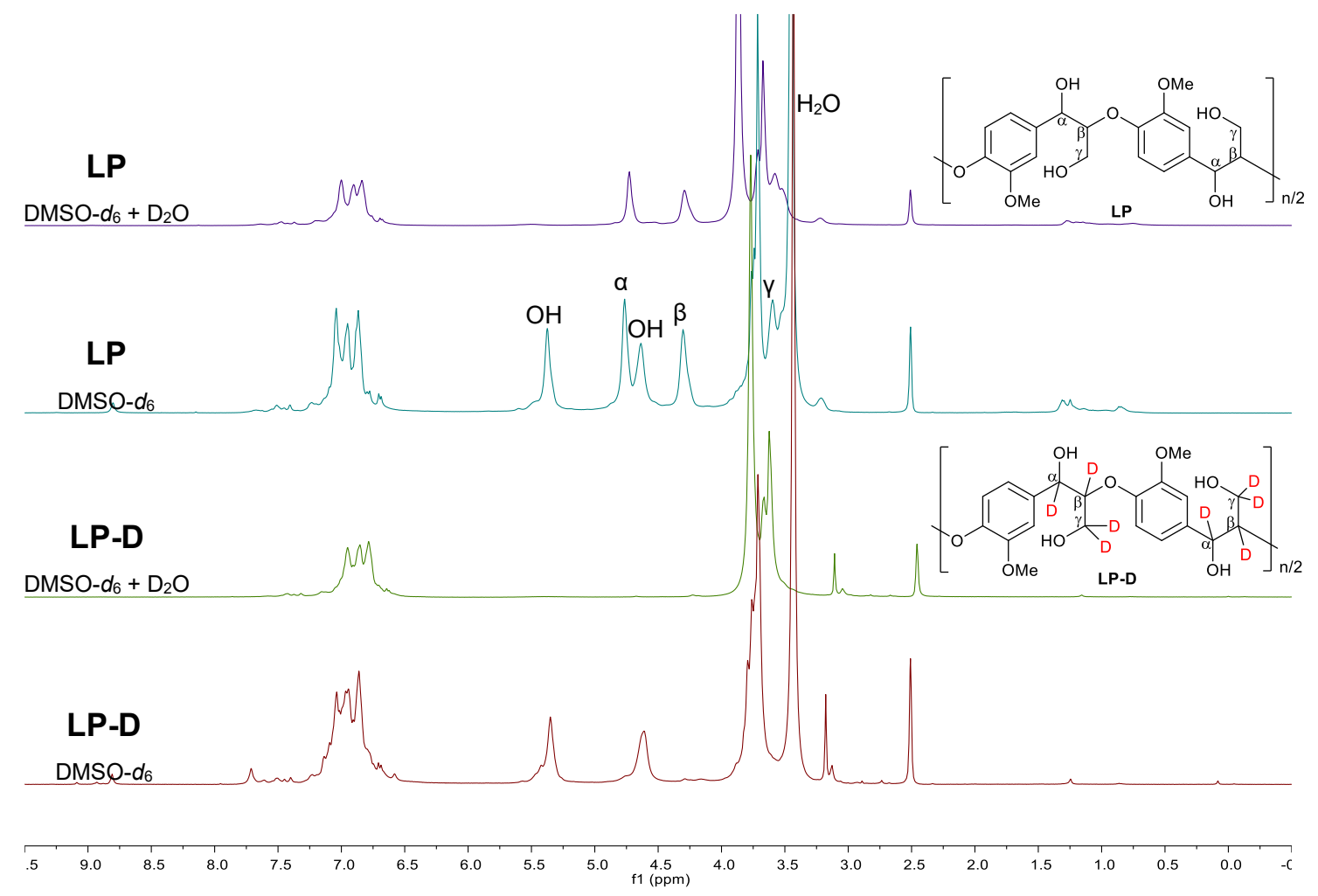




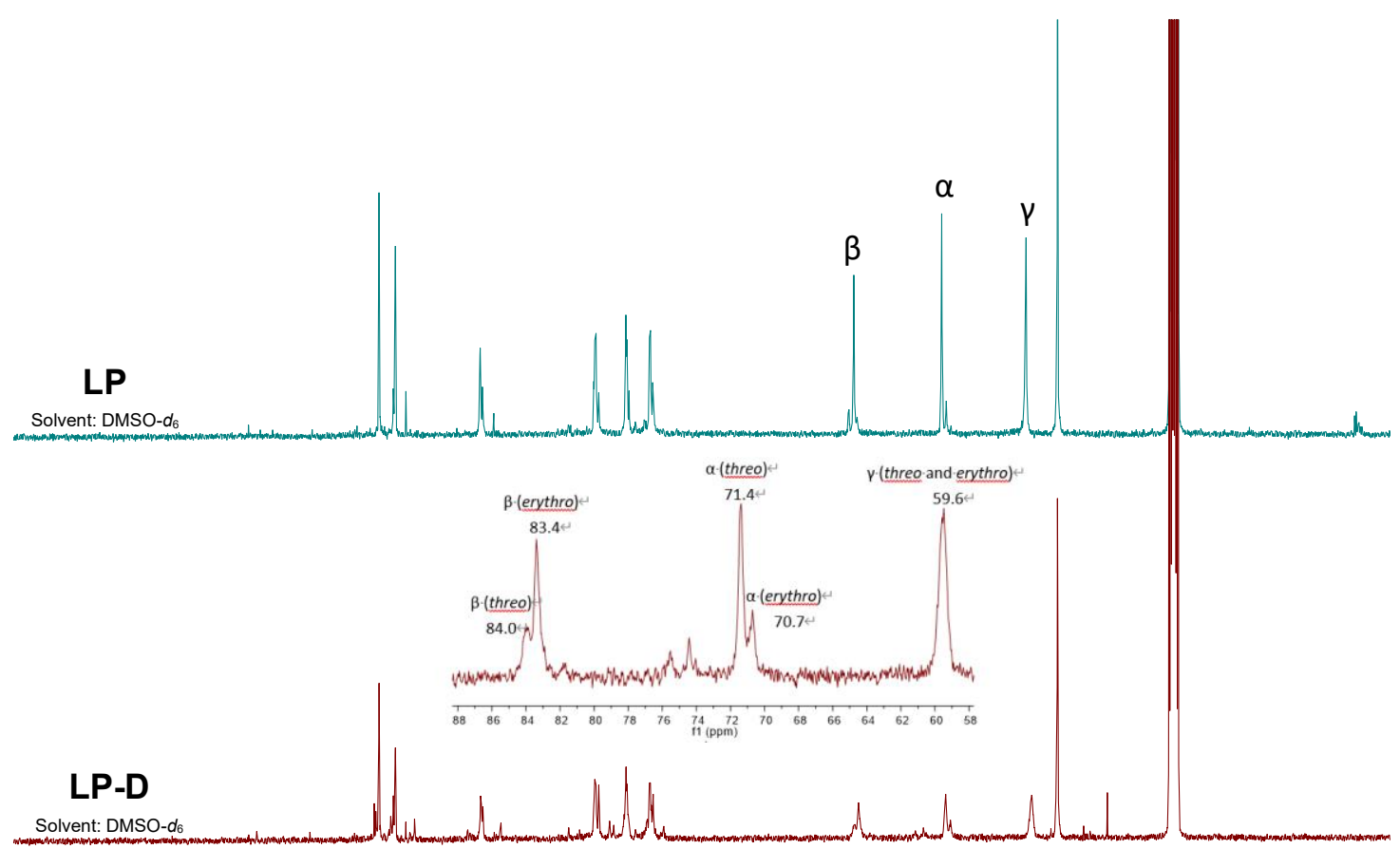

The signals of threo and erythro in $\beta-\mathrm{O}-4$ polymer were assigned by comparison with phenolic and non-phenolic lignin model dimers (as shown below). ${ }^{13}$

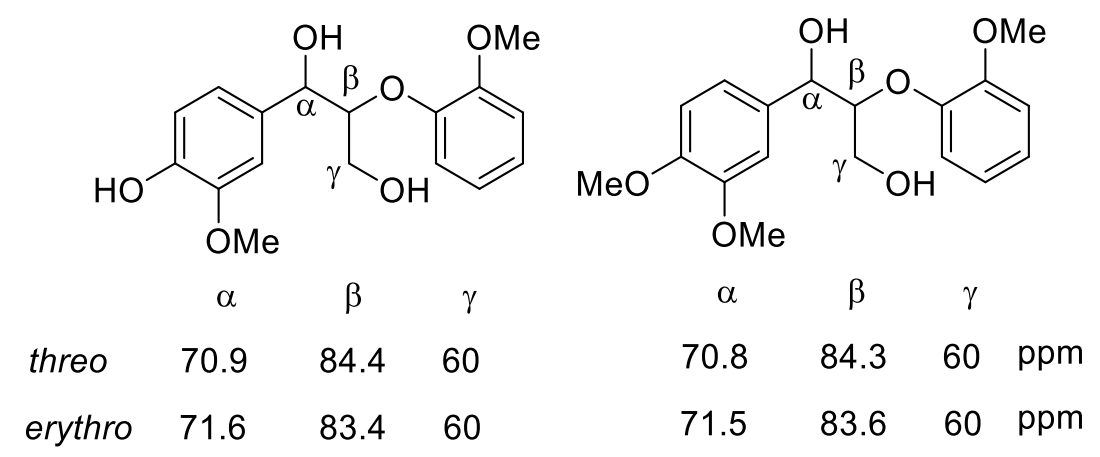

Figure S2. ${ }^{1} \mathrm{H}$ NMR and ${ }^{13} \mathrm{C}$ NMR spectra of LP and LP-D in DMSO- $d_{6}$. 


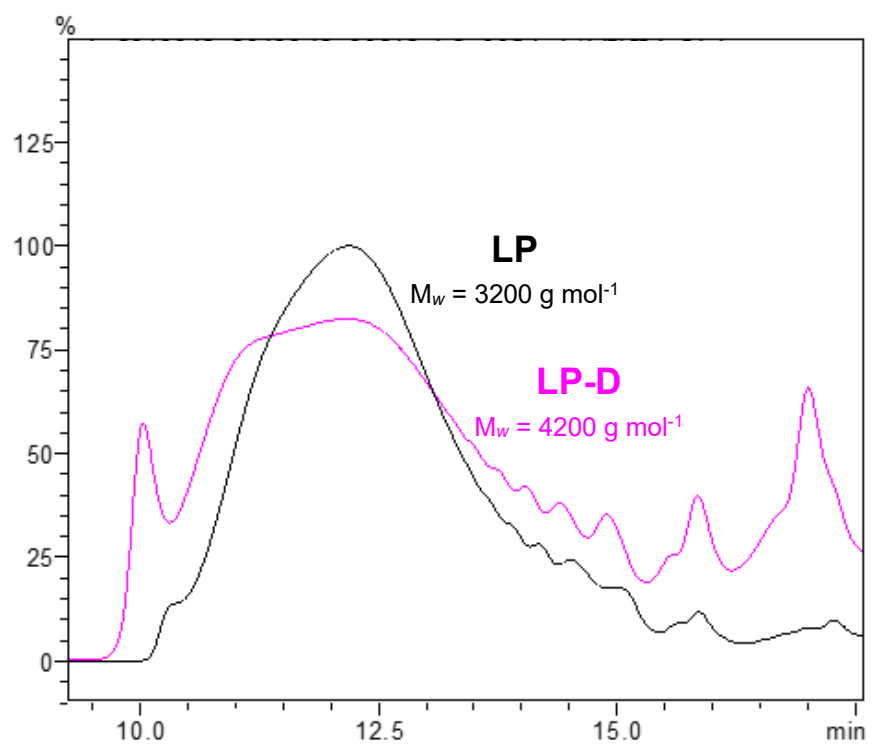

Figure S3. Molecular weight distribution of synthetic lignin polymer (LP) and deuterium lignin polymer (LP-D). 
The synthesis of 7-D1:

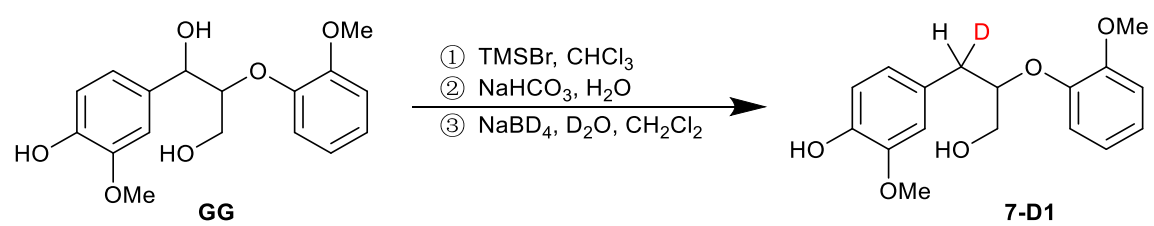

GG (192 mg, $0.6 \mathrm{mmol})$ was charged into separating funnel and dry $\mathrm{CH}_{2} \mathrm{Cl}_{2}(30 \mathrm{~mL})$ was added under $\mathrm{N}_{2}$ atmosphere. After injecting bromotrimethylsilane (TMSBr, $190 \mathrm{mg}, 1.2 \mathrm{mmol}$ ), the reaction solution was shaken for $1 \mathrm{~min}$. Saturated aqueous sodium bicarbonate $(10 \mathrm{~mL})$ was added to the solution to quench the reaction. The organic phase was then separated, dried by anhydrous $\mathrm{Na}_{2} \mathrm{SO}_{4}$. The removal the $\mathrm{Na}_{2} \mathrm{SO}_{4}$ via filtration gave a clear organic solution, to which $\mathrm{D}_{2} \mathrm{O}(10 \mathrm{~mL})$ and $\mathrm{NaBD}_{4}(126 \mathrm{mg}, 3 \mathrm{mmol})$ was added. After stirring at room temperature overnight, saturated $\mathrm{NH}_{4} \mathrm{Cl}$ solution was added to quench the reaction. The organic phase from the mixture was separated, dried over anhydrous $\mathrm{NaSO}_{4}$ and evaporated to give an oily product. 7-D1 was purified through silica gel column chromatography with PE/EtOAc (2:1) as syrup (165 mg, 90\%). ${ }^{1} \mathbf{H}$ NMR (400 $\left.\mathrm{MHz}, \mathrm{CDCl}_{3}\right): \delta 7.03-6.75(\mathrm{~m}, 7 \mathrm{H}), 5.56(\mathrm{~s}, 1 \mathrm{H}), 4.25-4.22(\mathrm{~m}, 1 \mathrm{H}), 3.88(\mathrm{~s}, 3 \mathrm{H}), 3.85(\mathrm{~s}, 3 \mathrm{H})$, $3.71-3.60(\mathrm{~m}, 2 \mathrm{H}), 3.06-2.88(\mathrm{~m}, 1 \mathrm{H}), 2.98(\mathrm{t}, 1 \mathrm{H}) ;{ }^{13} \mathbf{C}$ NMR $\left(100 \mathrm{MHz}, \mathrm{CDCl}_{3}\right): \delta 151.5,147.7$, 146.6, 144.4, 129.8, 123.6, 122.3, 121.6, 120.2, 114.5, 112.3, 85.3, 63.6, 56.1, 56.0, 37.1 (d, $J=17.7$ $\mathrm{Hz}, \alpha-\mathrm{C})$. 


\section{Hydrogenolysis of LP-D with Ru/C catalyst}

General procedure: In a $50 \mathrm{~mL}$ autoclave with a magnetic stirring bar, lignin model compound LP-D $(60 \mathrm{mg}), \mathrm{Ru} / \mathrm{C}(3 \mathrm{mg}, 5 \mathrm{wt} \%)$ and $\mathrm{MeOH}(10 \mathrm{~mL})$ were charged and sealed, which was then evacuated and filled with $\mathrm{H}_{2}(30 \mathrm{~atm})$ at room temperature. After stirring at $180{ }^{\circ} \mathrm{C}$ for $12 \mathrm{~h}$, the autoclave was cooled to room temperature and depressurized carefully, to which tetradecane $(0.005$ mmol) was added as a standard. The reaction mixture was filtered and the filtrates were evaporated to afford an oily product. The oily product was dissolved into $\mathrm{CH}_{2} \mathrm{Cl}_{2}$ in a $5.0 \mathrm{~mL}$ volumetric flask, which was then submitted to GC and GC-MS. The identification and quantification of products were assessed by comparison with authentic samples.

Compounds $\mathbf{4}$ and $\mathbf{5}$ could be separated and purified through silica gel column chromatography (PE/EtOAc), which were then characterized by NMR. ${ }^{1} \mathrm{H}$ NMR and mass analyses suggested that all deuteriums still preserved at $\alpha, \beta$ and $\gamma$ positions.
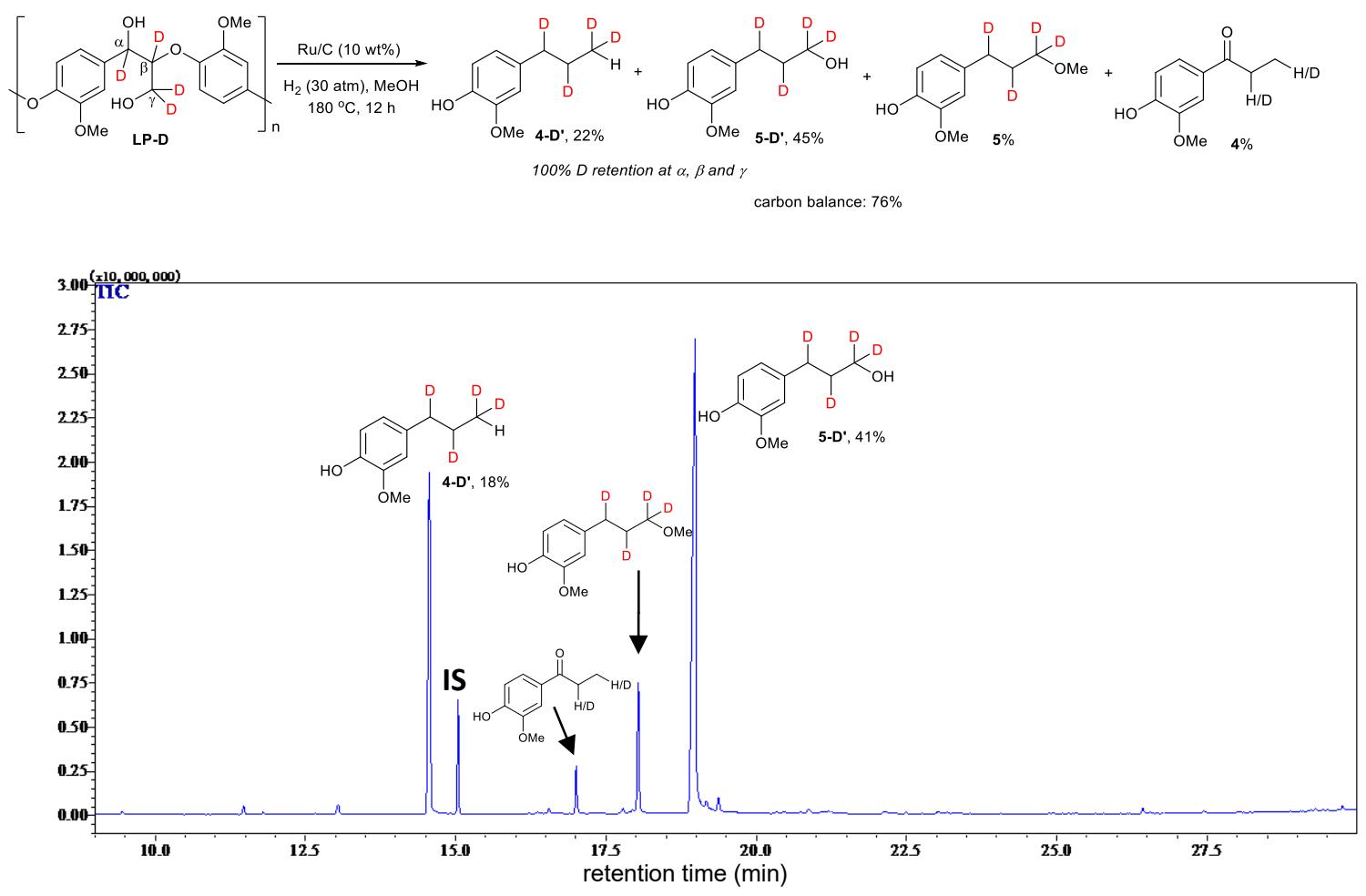

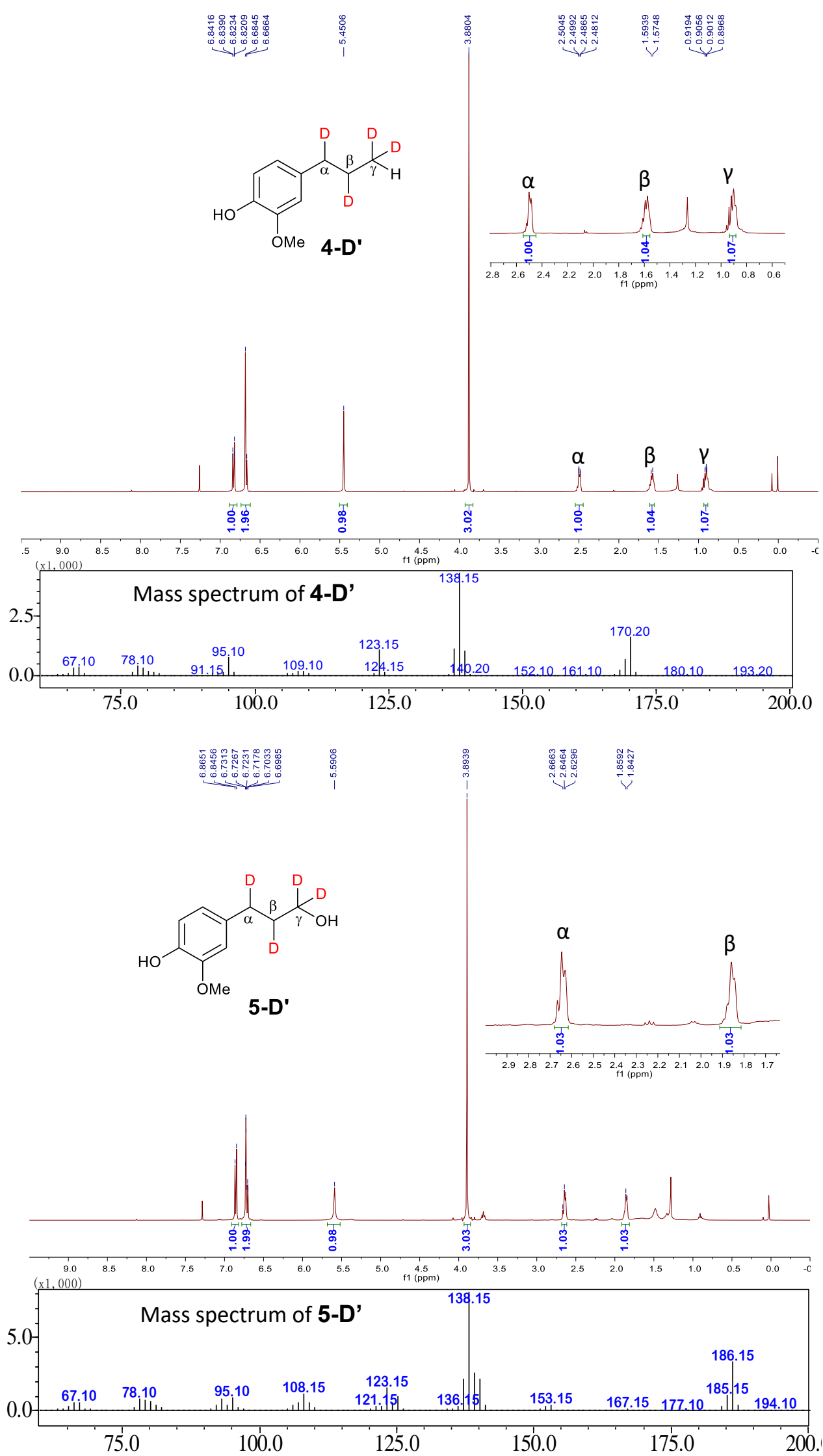

Figure S4. GC-MS, 'H NMR and mass spectra of 4-D' and 5-D' from the hydrogenolysis of LP-D with $\mathrm{Ru} / \mathrm{C}$. 


\section{Hydrogenolysis of deuterium-incorporated $\beta-\mathrm{O}-4$ mimics with $\mathrm{Pd} / \mathrm{C}$ catalyst}

\section{Decomposition of VG-D with Pd/C catalyst}

This reaction was conducted with $30 \mathrm{wt} \% \mathrm{Pd} / \mathrm{C}$ and $180{ }^{\circ} \mathrm{C}$ for $3 \mathrm{~h}$. After reaction, silica gel column chromatography (PE/EtOAc) gave a mixture containing compound 3-D, $\mathbf{6}$ and VG-D-OMe. The identification and quantification of 3-D, 6, VG-D-OMe and guaiacol were assessed on GC-MS by comparison with authentic samples. In 3-D, $27 \%$ of $\alpha$-D has been replaced with $H$, and $\beta-D$ retained well.

In the case of $5 \mathrm{wt} \% \mathrm{Pd} / \mathrm{C}$, the yields of $\mathbf{3}$, guaiacol, VG-D-OMe and $\mathbf{6}$ were determined as $12 \%$, $14 \%, 69 \%$ and $6 \%$, respectively.
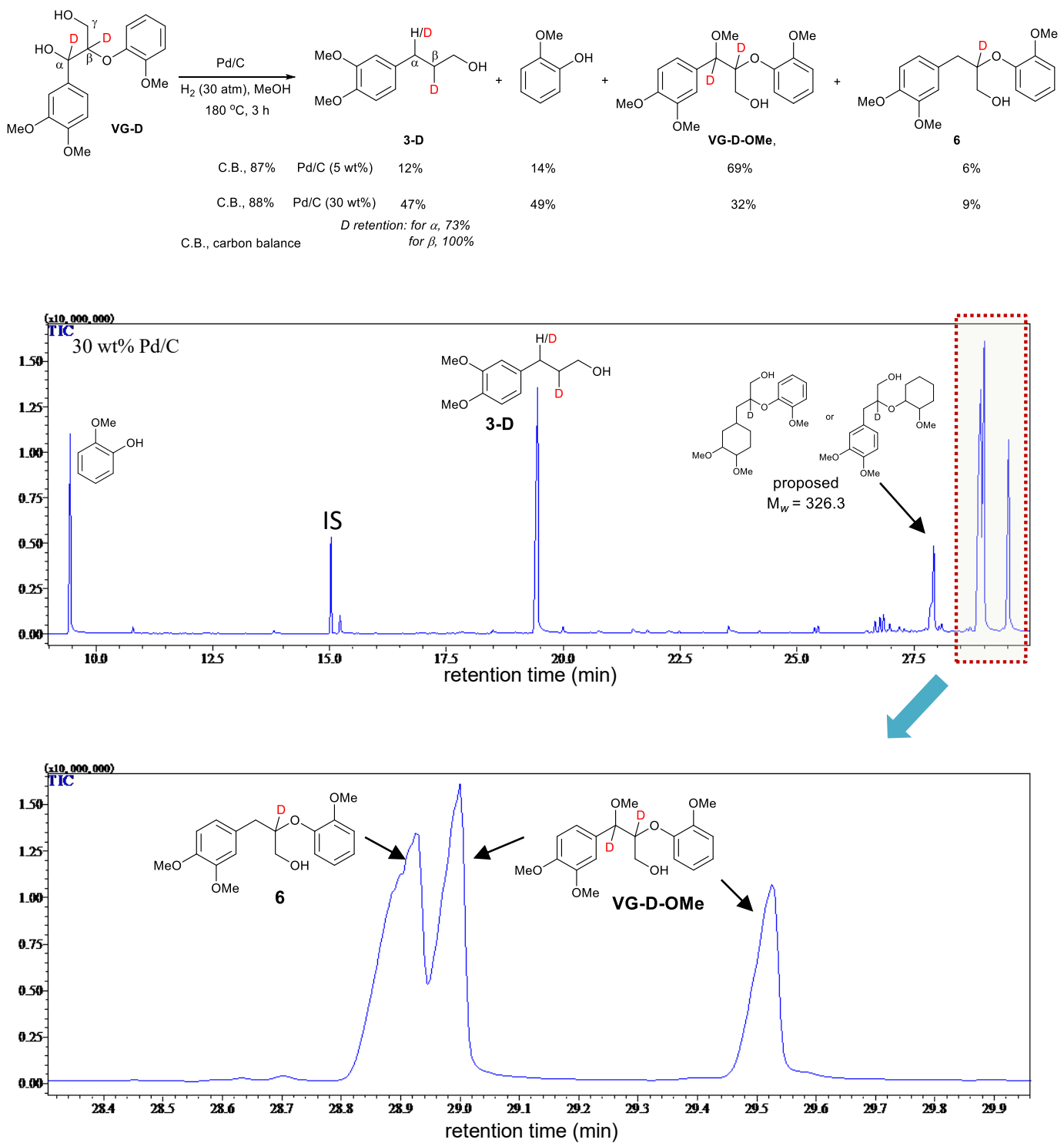

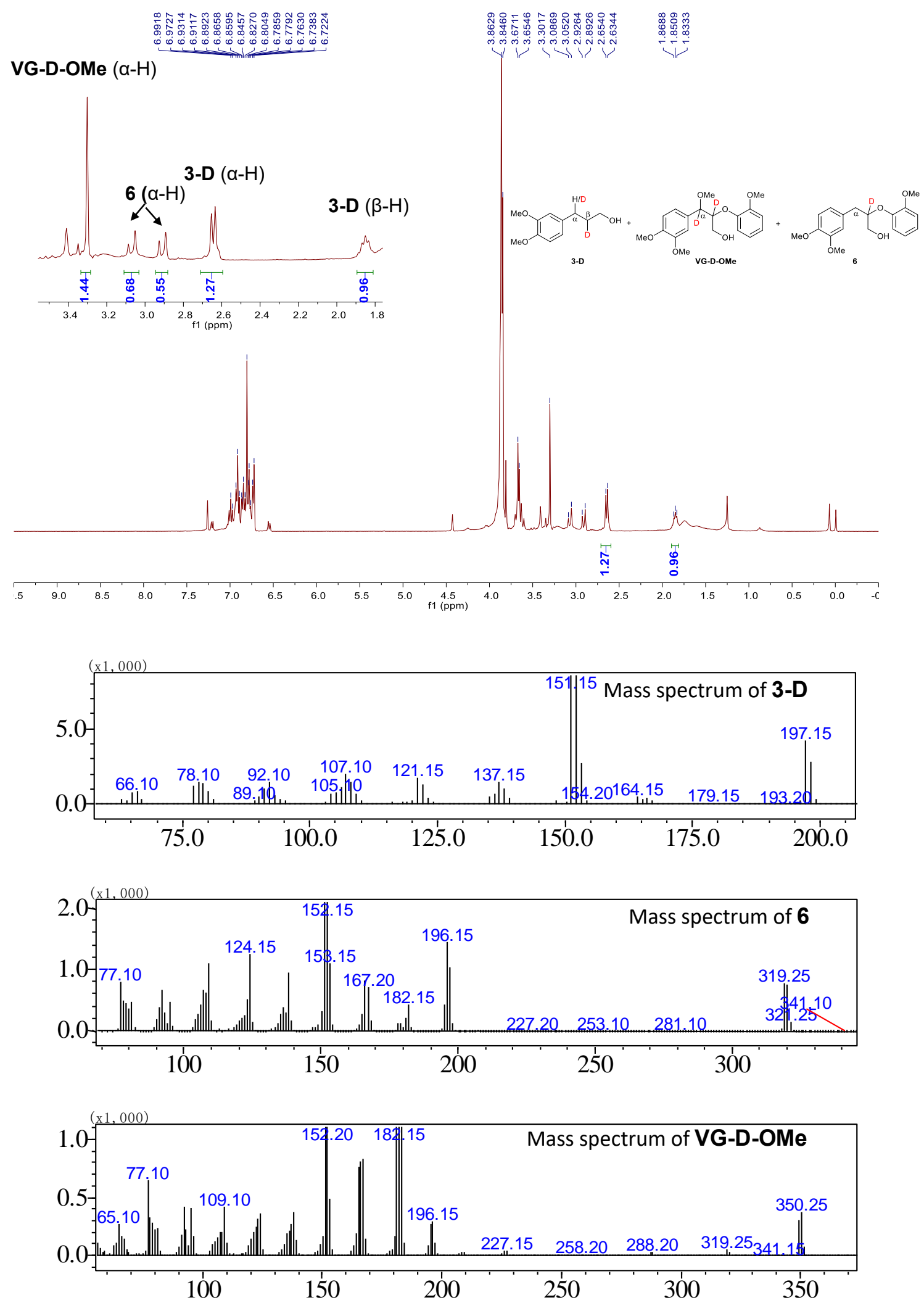

Figure S5. GC-MS, ${ }^{1} \mathrm{H}$ NMR and mass spectra of the products from the hydrogenolysis of VG-D with $\mathrm{Pd} / \mathrm{C}$. 


\section{Decomposition of GG-D with $\mathrm{Pd} / \mathrm{C}$ catalyst}

These reactions were conducted according to the General procedure by using GG-D (60 mg) and $\mathrm{Pd} / \mathrm{C}(3 \mathrm{mg})$ at $150{ }^{\circ} \mathrm{C}, 180{ }^{\circ} \mathrm{C}, 220^{\circ} \mathrm{C}$ and $250{ }^{\circ} \mathrm{C}$ for $3 \mathrm{~h}$. After reaction, silica gel column chromatography (PE/EtOAc) gave a mixture containing compound 5, 7 and guaiacol. The identification and quantification of 5, 7 and guaiacol were assessed on GC-MS by comparison with authentic samples.
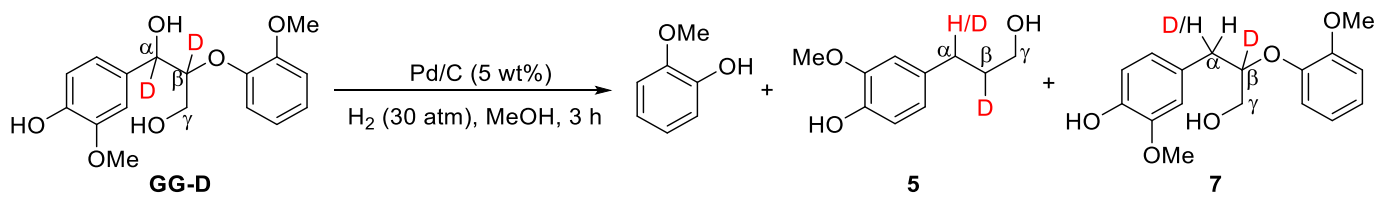

Table S1. Catalytic depolymerization of GG-D under different conditions ${ }^{\mathrm{a}}$

\begin{tabular}{|c|c|c|c|c|c|c|c|c|c|}
\hline \multirow[t]{2}{*}{ entry } & \multirow{2}{*}{$\begin{array}{c}\text { temperature } \\
\left({ }^{\circ} \mathrm{C}\right)\end{array}$} & yields & \multicolumn{2}{|c|}{$(\%)$} & \multirow{2}{*}{$\begin{array}{l}\text { C.B. } \\
(\%)^{\mathrm{b}}\end{array}$} & \multicolumn{2}{|c|}{$\begin{array}{c}\text { D retention } \\
\text { of } 5(\%)\end{array}$} & \multicolumn{2}{|c|}{$\begin{array}{c}\text { D retention of } \\
7(\%)^{\mathrm{c}}\end{array}$} \\
\hline & & guaiacol & 5 & 7 & & $\alpha$ & $\beta$ & $\alpha$ & $\beta$ \\
\hline 1 & 150 & 54 & 43 & 40 & 87 & 100 & 100 & 50 & 100 \\
\hline 2 & 180 & 67 & 64 & 26 & 91 & 100 & 100 & 0 & 100 \\
\hline 3 & 220 & 76 & 70 & 20 & 90 & 92 & 100 & - & - \\
\hline 4 & 250 & 83 & 78 & 8 & 87 & 37 & 100 & - & - \\
\hline
\end{tabular}

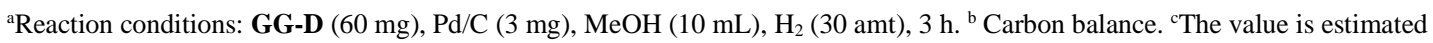
by NMR spectra.

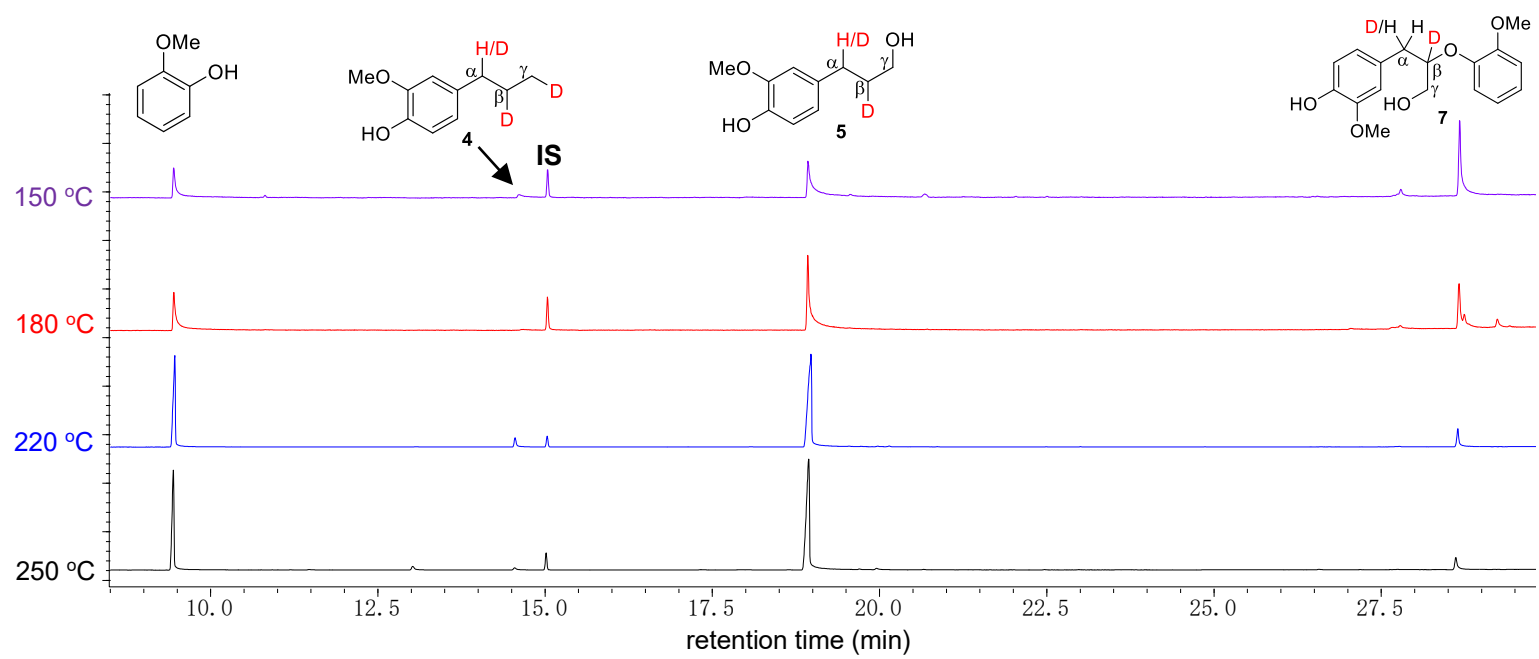


$150{ }^{\circ} \mathrm{C}$ :

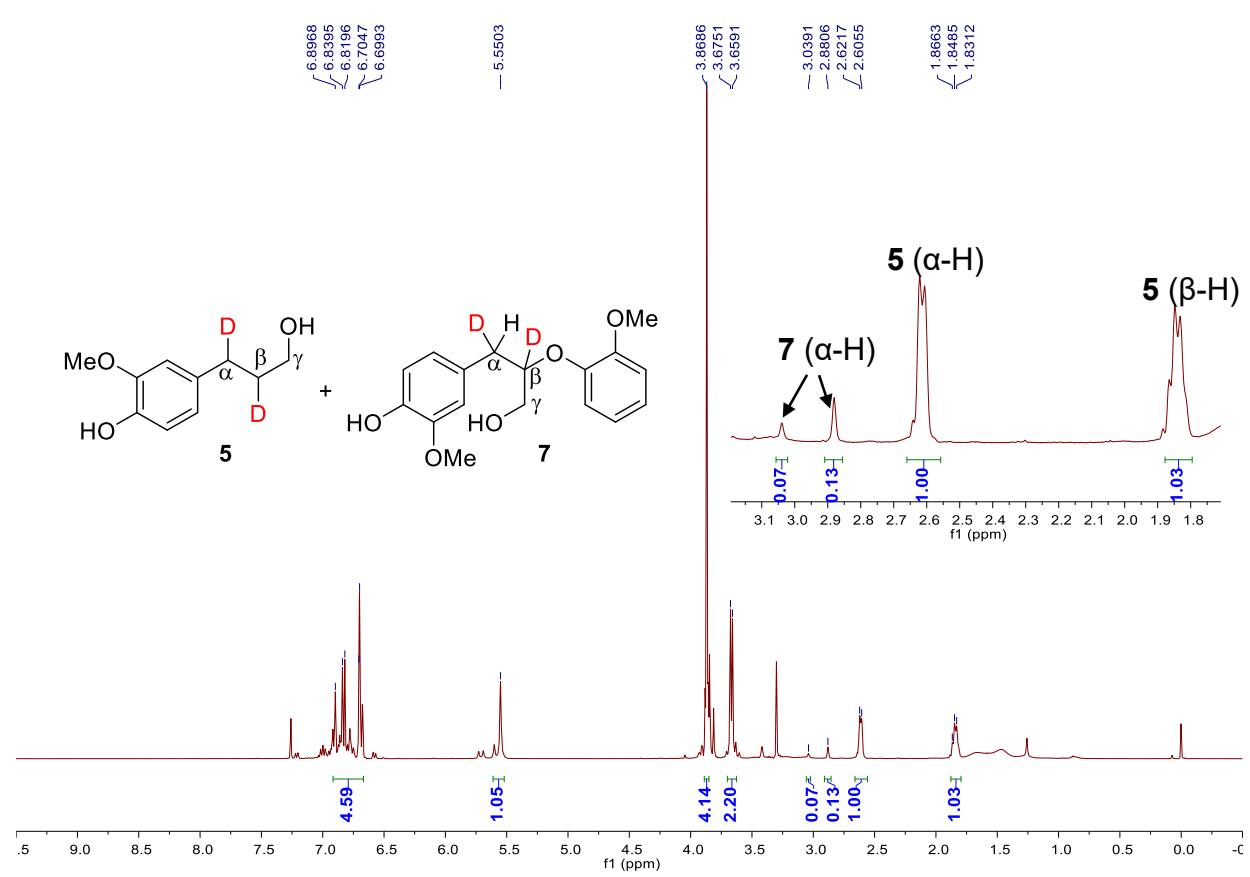

$180^{\circ} \mathrm{C}$ :

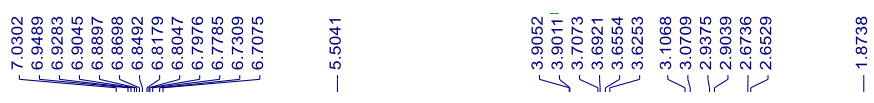

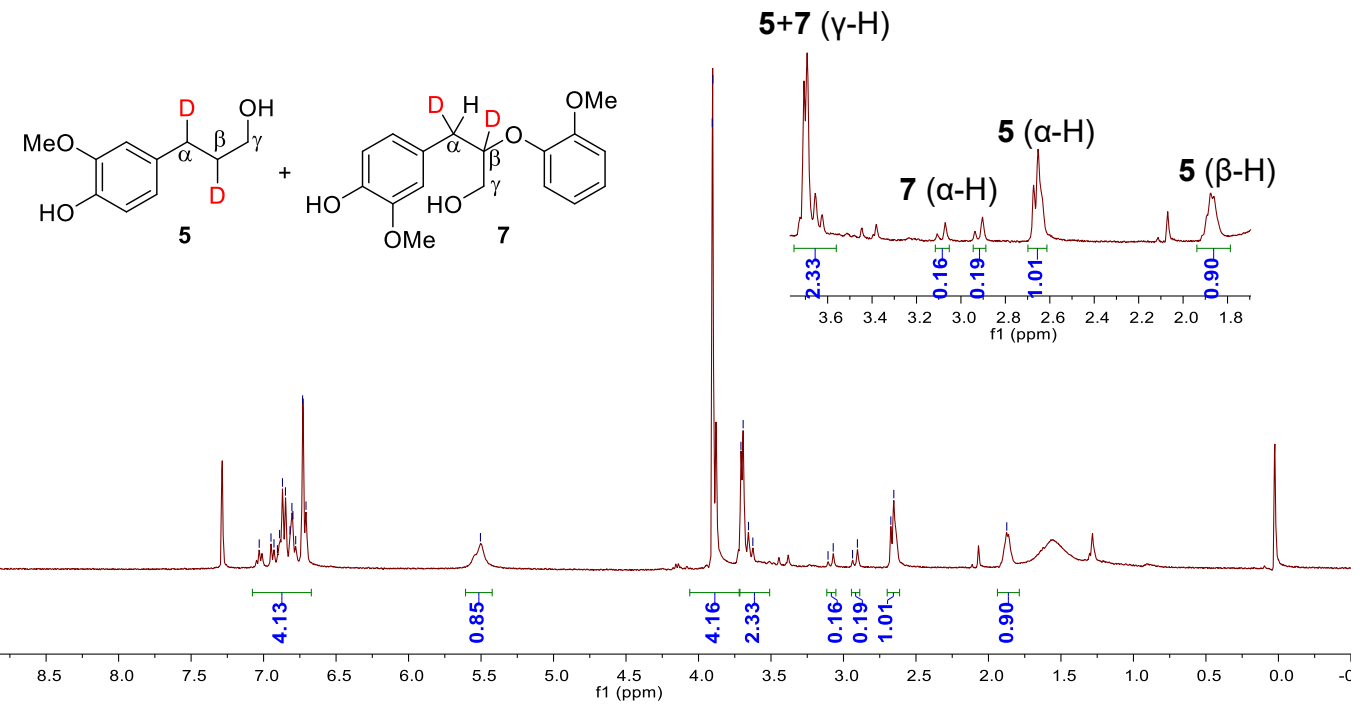


$220^{\circ} \mathrm{C}$ :

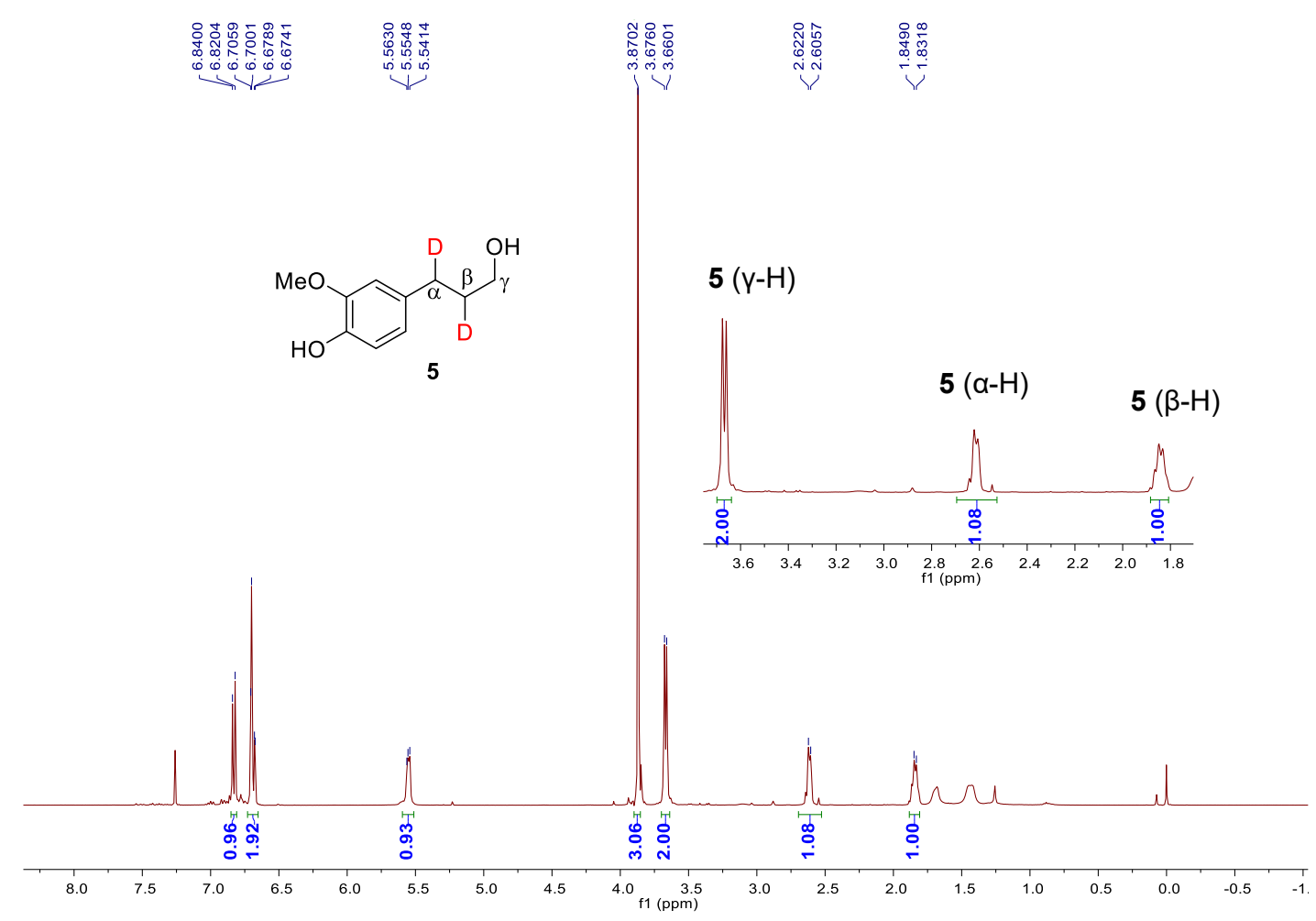

$250^{\circ} \mathrm{C}$ :

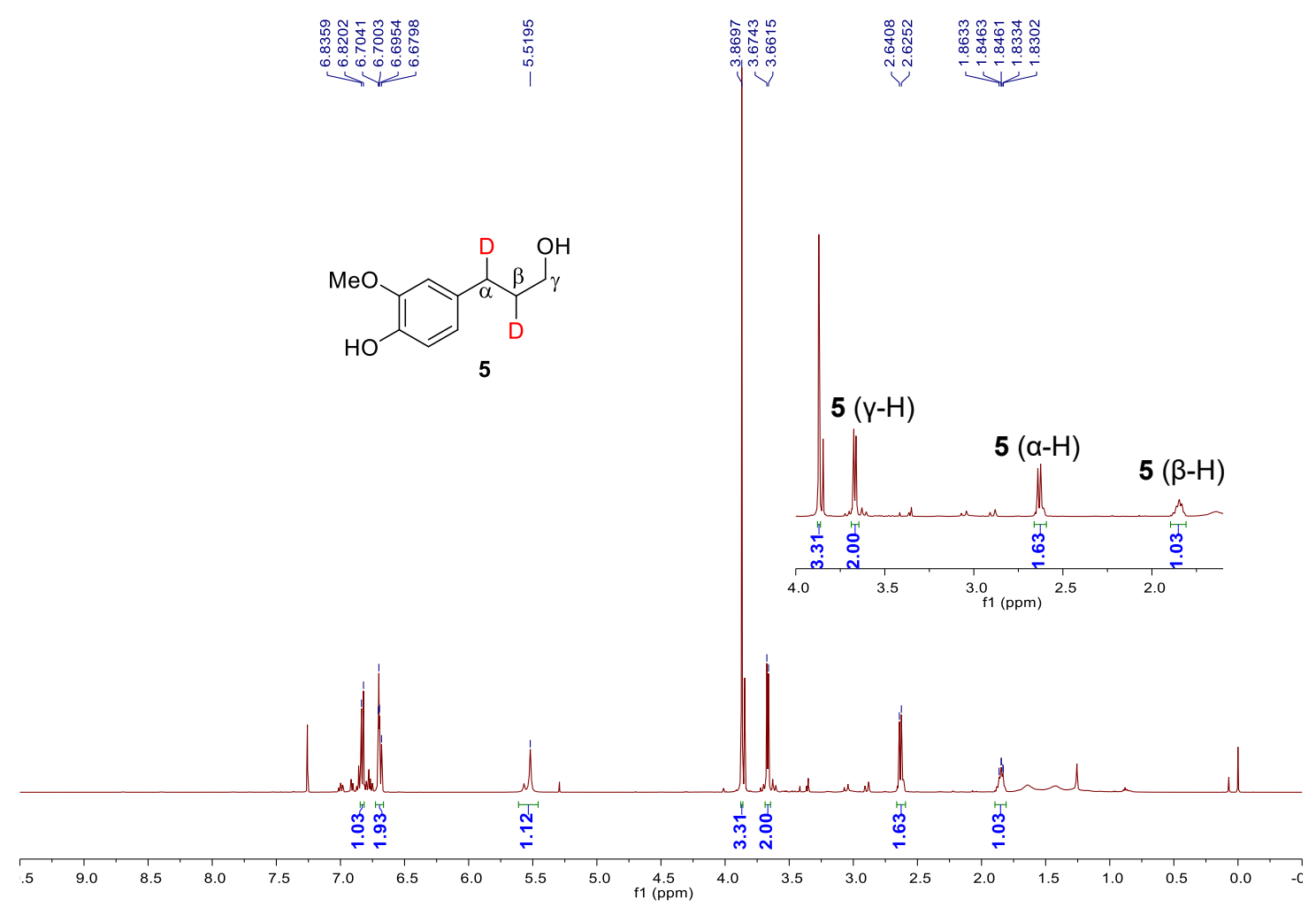

Figure S6. GC-MS and ${ }^{1} \mathrm{H}$ NMR spectra of the products from the hydrogenolysis of GG-D with $\mathrm{Pd} / \mathrm{C}$ 


\section{Treatment of 5-D with $\mathrm{Pd} / \mathrm{C}$ in $\mathrm{H}_{2}$ for $3 \mathrm{~h}$.}

These reactions were conducted at $220{ }^{\circ} \mathrm{C}(3 \mathrm{~h}), 250{ }^{\circ} \mathrm{C}(3 \mathrm{~h})$ and $210{ }^{\circ} \mathrm{C}(12 \mathrm{~h})$, respectively. After reaction, the mixture was filtrated and the solvent was evaporated in vacuo. Then the obtained crude product was characterized by ${ }^{1} \mathrm{H}$ NMR. $\alpha$-D retention $(2.66-2.64 \mathrm{ppm})$ was estimated by the integration of ${ }^{1} \mathrm{H}$ NMR spectra.
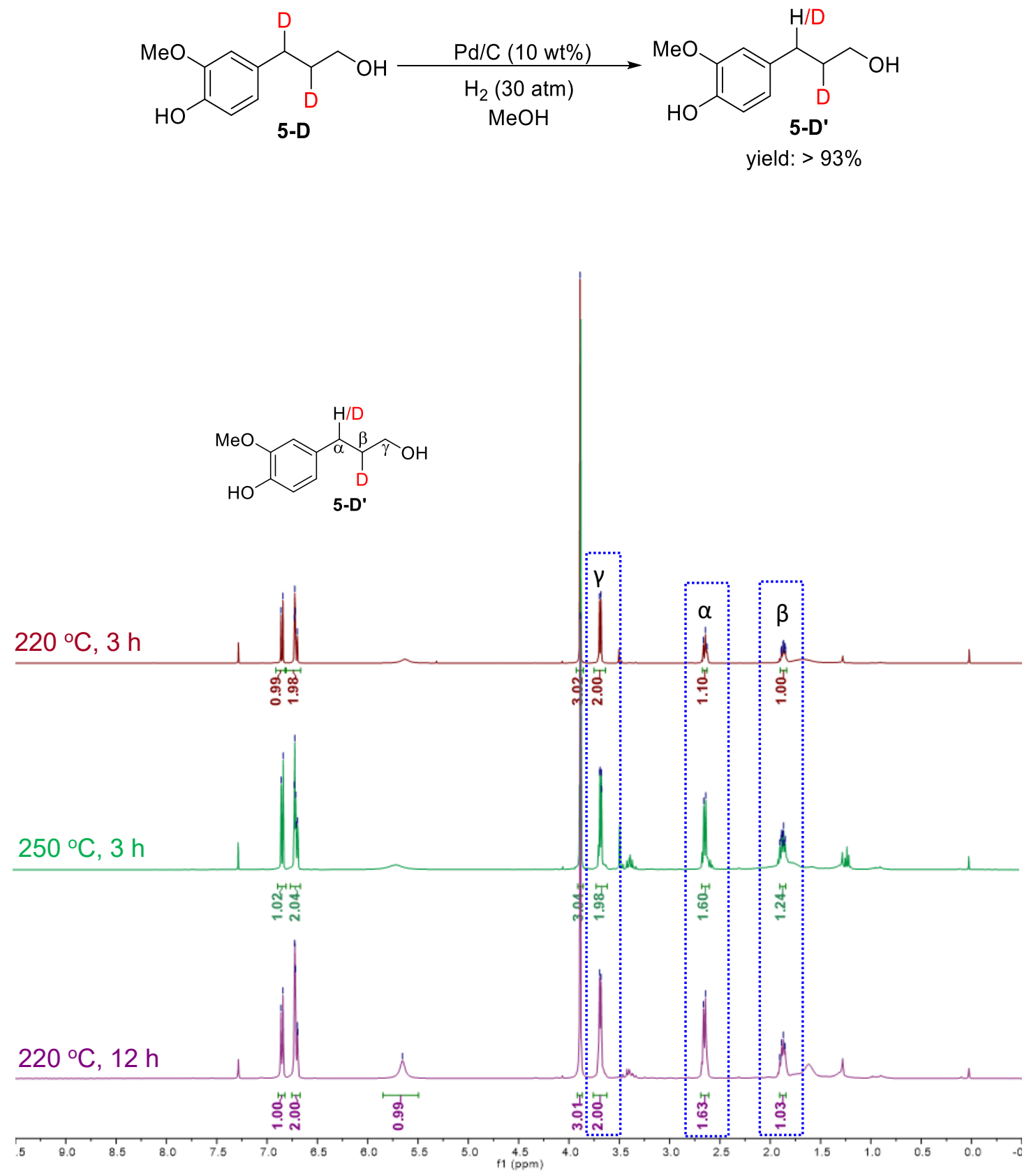

Figure S7. 'H NMR spectra of 5-D' from the treatment of 5-D by Pd/C under different temperatures. 


\section{Treatment of 7-D1 with $\mathrm{Pd} / \mathrm{C}$ in $\mathrm{H}_{2}$.}

This reaction was conducted according to the General procedure at $220^{\circ} \mathrm{C}$. After reaction, the mixture was filtrated and the solvent was evaporated in vacuo. The obtained crude product was characterized by ${ }^{1} \mathrm{H}$ NMR. The integration of $\alpha-\mathrm{H}$ resonated at 3.10-3.03 ppm and 2.94-2.85 ppm indicated that the $\alpha-\mathrm{D}$ in 7-D1 has been lost after treatment.
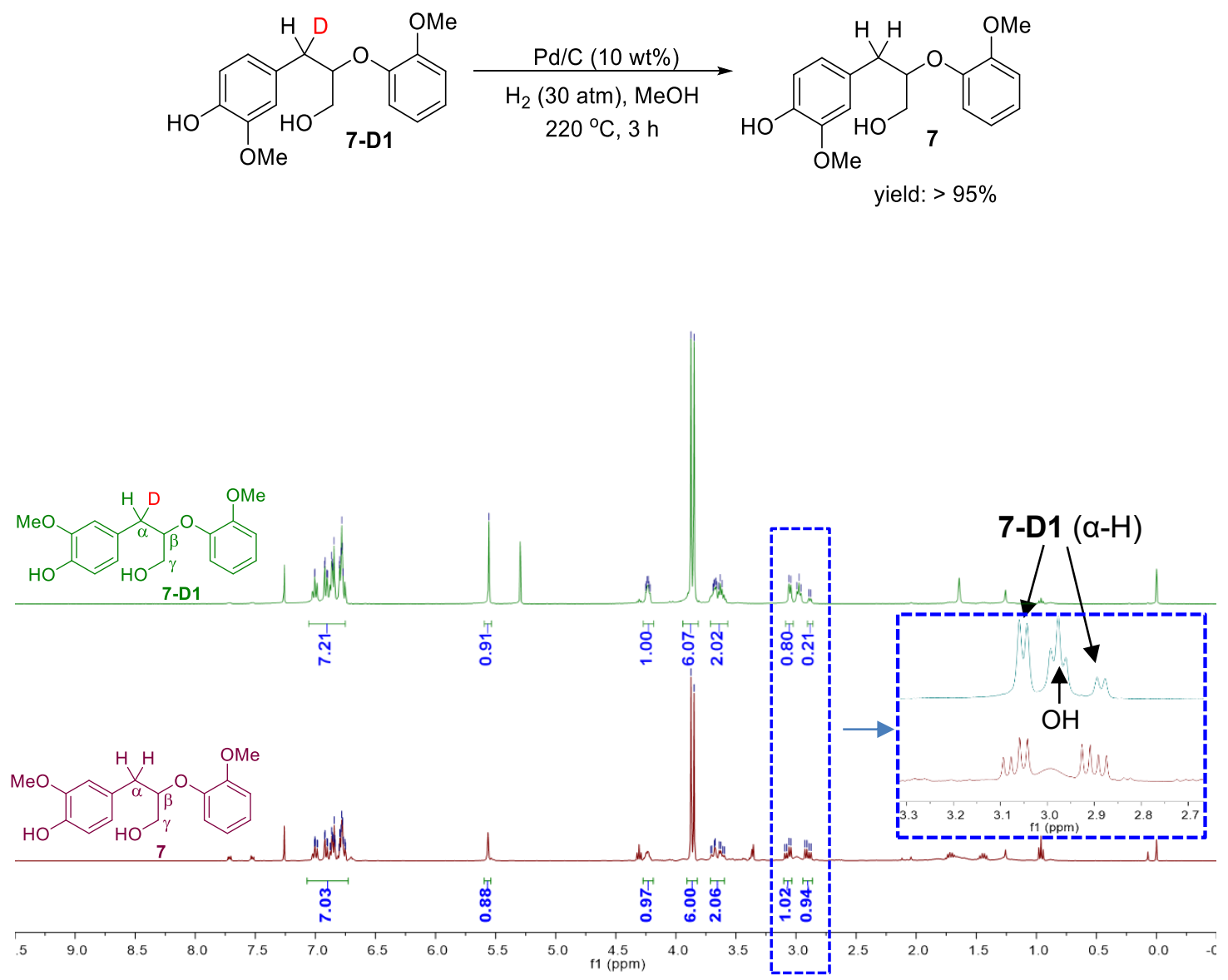

Figure S8. ${ }^{1} \mathrm{H}$ NMR spectra of 7 from the treatment of 7-D1 by Pd/C. 


\section{Treatment of GG-D with $\mathrm{Pd} / \mathrm{C}$ in $\mathbf{N}_{\mathbf{2}}$.}

This reaction was conducted according to the General procedure under nitrogen atmosphere (1 atm at room temperature) at $220{ }^{\circ} \mathrm{C}$. After reaction, the mixture was filtrated and the solvent was evaporated in vacuo. Then the obtained crude product was characterized by GC-MS and NMR. The identification of $\mathbf{8}$ was assessed on GC-MS by comparison with corresponding deuterium authentic samples. The absence of signals at $6.33\left(\mathrm{H}_{\alpha}\right)$ and $6.08\left(\mathrm{H}_{\beta}\right)$ ppm indicated that D-atoms were retained well in 8-D.

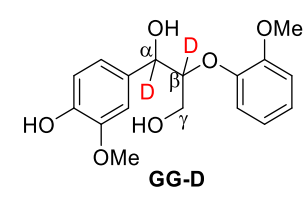

$\underset{\mathrm{N}_{2}(1 \mathrm{~atm}), \mathrm{MeOH}}{\mathrm{Pd} / \mathrm{C}(5 \mathrm{wt} \%)}$

$220^{\circ} \mathrm{C}, 3 \mathrm{~h}$

Carbon balance: $78 \%$

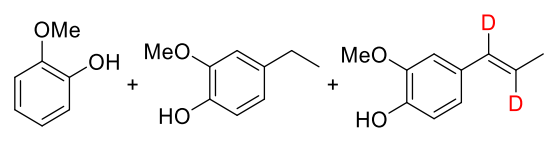

$87 \% \quad 14 \%$ 8-D, $50 \%$

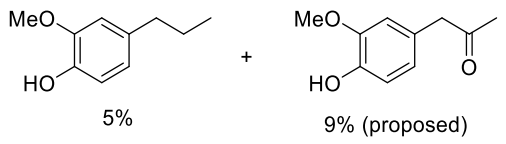

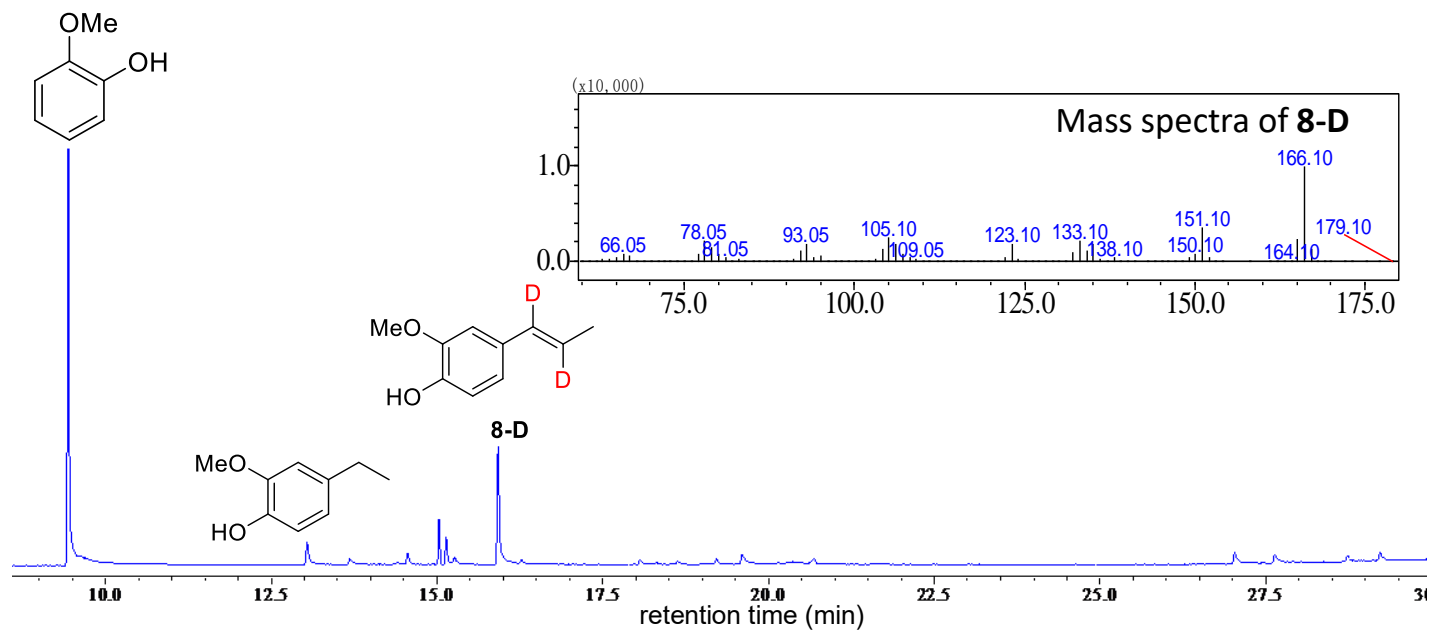




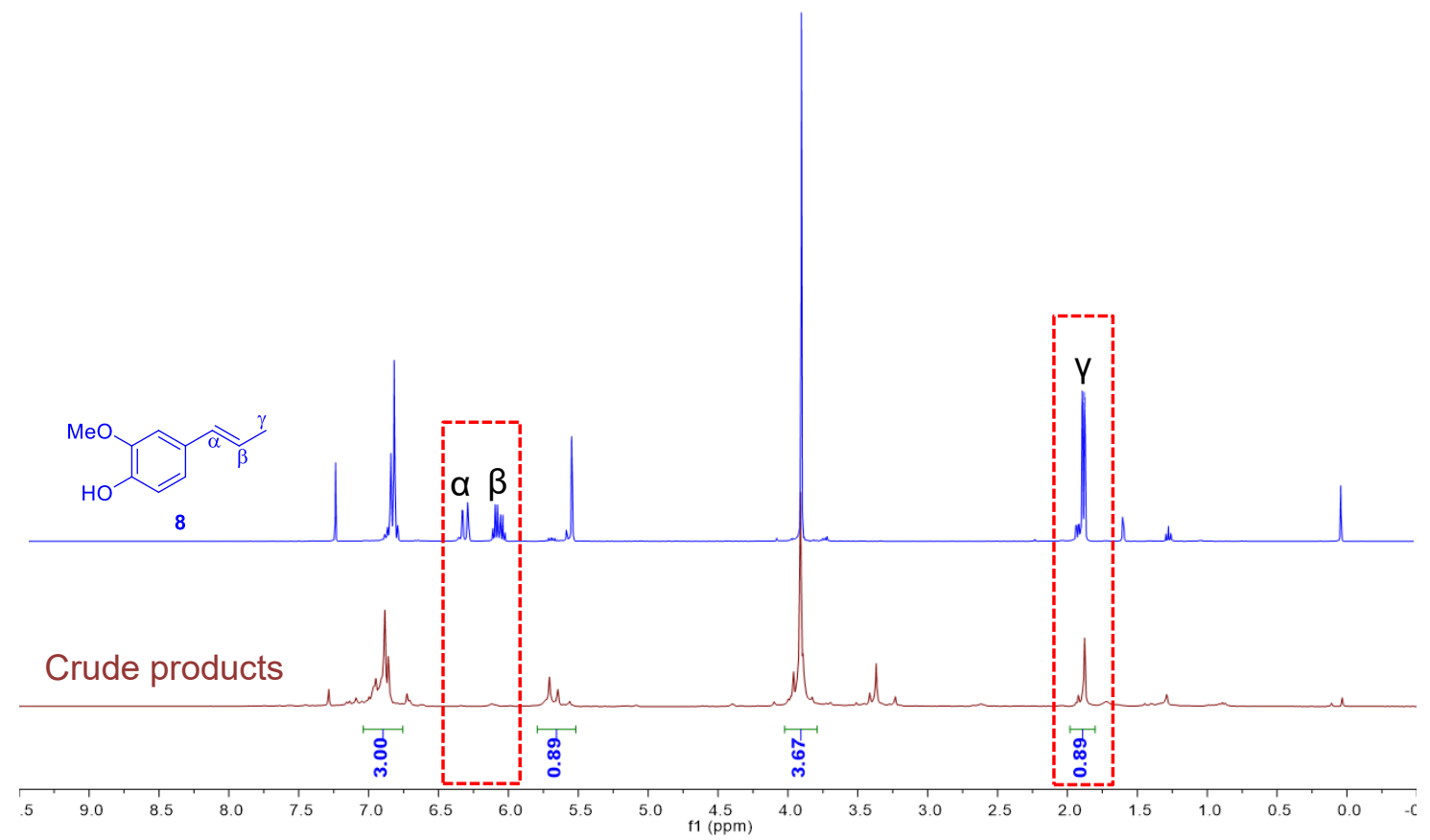

Figure S9. GC-MS and ${ }^{1} \mathrm{H}$ NMR spectra of the products from hydrogenolysis of GG-D with $\mathrm{Pd} / \mathrm{C}$ under $\mathrm{H}_{2}$-free condition. 


\section{Depolymerization of LP-D with $\mathrm{Pd} / \mathrm{C}$ at different temperature.}

These reactions were conducted according to the General procedure by using LP-D $(60 \mathrm{mg})$, $\mathrm{Pd} / \mathrm{C}(6 \mathrm{mg}, 10 \mathrm{wt} \%)$ at $180^{\circ} \mathrm{C}, 220^{\circ} \mathrm{C}$ and $250^{\circ} \mathrm{C}$ for $12 \mathrm{~h}$. The identification and quantification of 5-D' was assessed on GC-MS by comparison with corresponding authentic samples. After reaction, silica gel column chromatography (PE/EtOAc) gave compound 5-D' as syrup in a pure manner.

Table S2. Pd/C-catalysed hydrogenolysis of LP-D under different temperatures

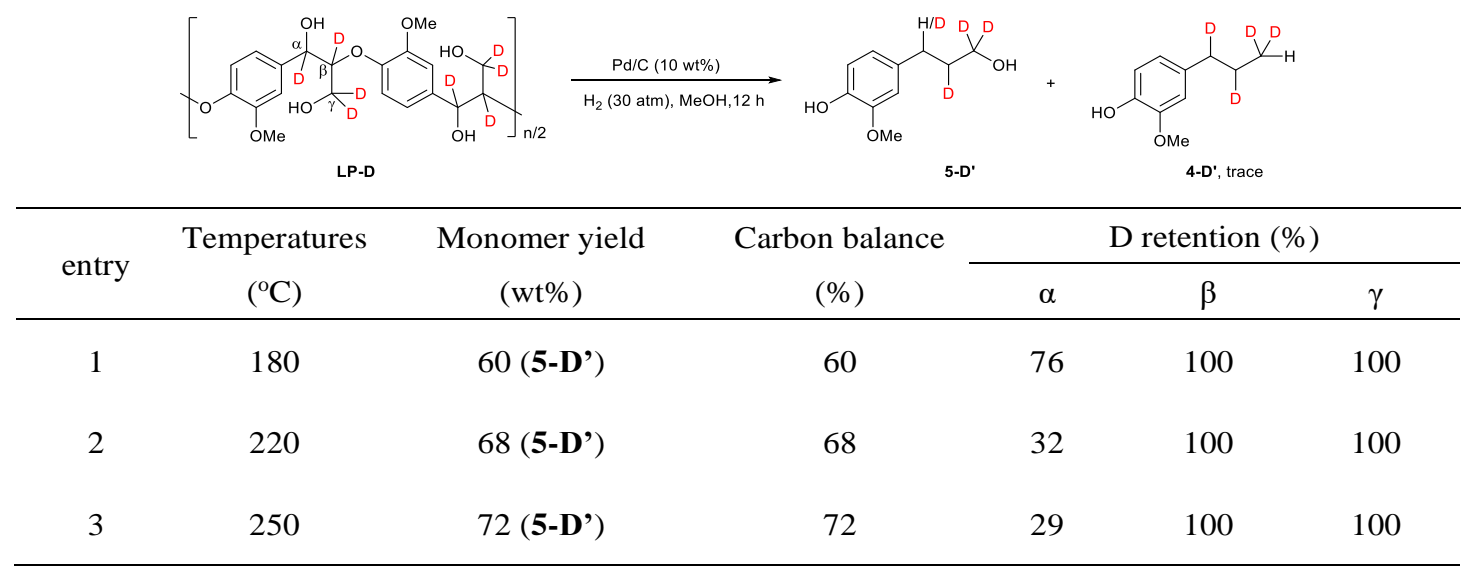

Reaction conditions: LP-D (60 mg), Pd/C (6 mg), MeOH (10 mL), $\mathrm{H}_{2}(30 \mathrm{~atm}), 12 \mathrm{~h}$.

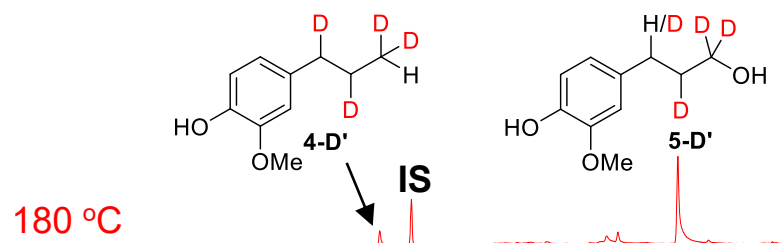

$220^{\circ} \mathrm{C}$

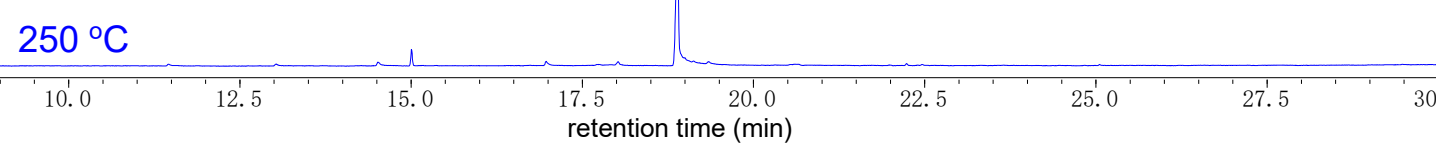




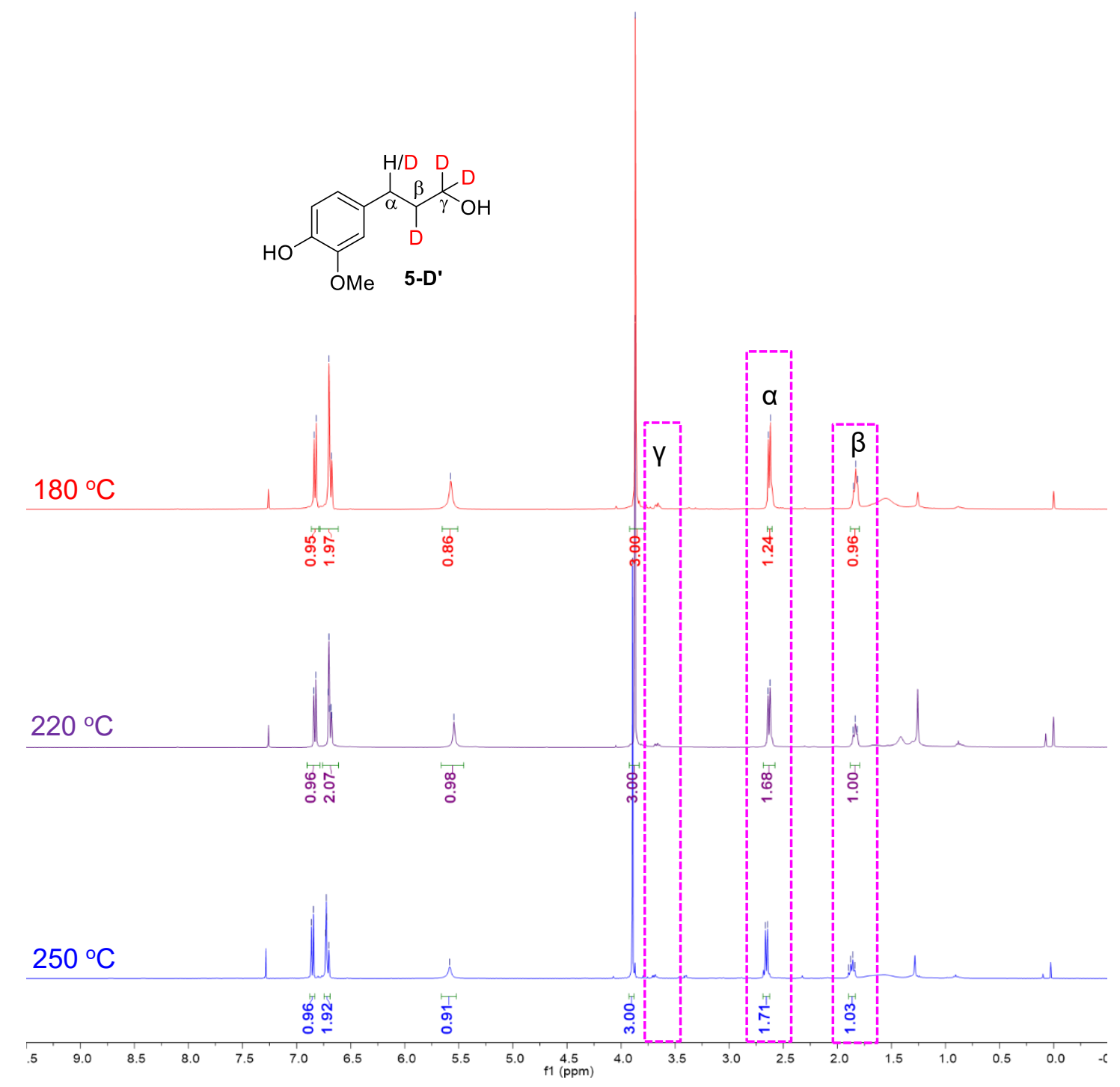

Mass spectrum of 5-D':

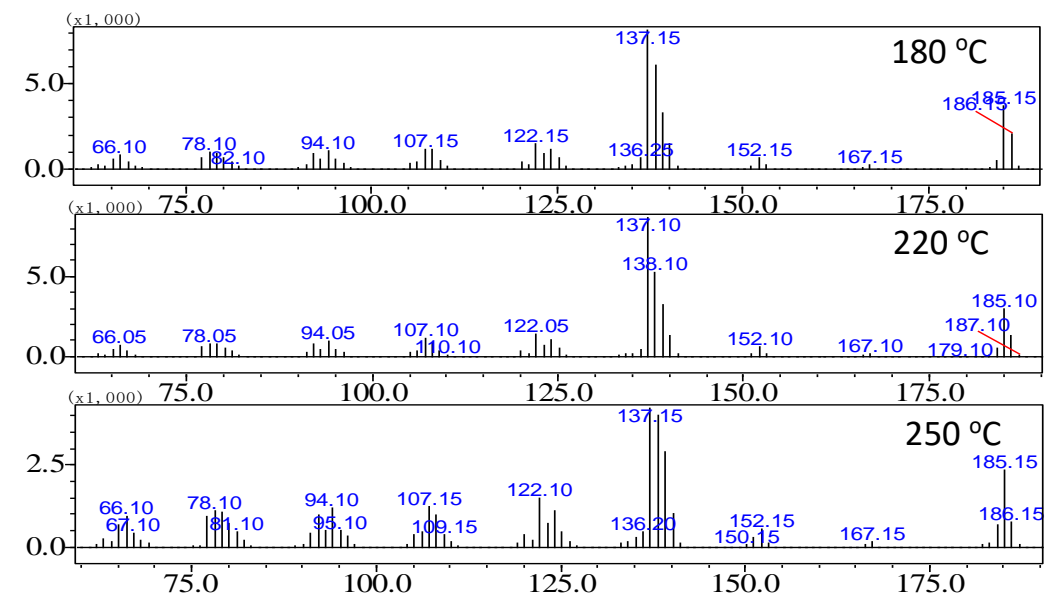

Figure S10. Characterizations of depolymerized products from hydrogenolysis of LP-D with $\mathrm{Pd} / \mathrm{C}$ under $\mathrm{H}_{2}$. 


\section{Depolymerization of LP-D with Pd/C under $\mathrm{N}_{2}$ atmosphere.}

This reaction was conducted according to the General procedure by using LP-D (60 mg) and $\mathrm{Pd} / \mathrm{C}\left(6 \mathrm{mg}, 10 \mathrm{wt}^{\%}\right)$ at $250{ }^{\circ} \mathrm{C}$ under $\mathrm{N}_{2}(1 \mathrm{~atm}$ at room temperature) for $12 \mathrm{~h}$. After reaction, the mixture was filtered, evaporated and purified by silica gel column chromatography (PE/EtOAc). A mixture containing 8-D' was obtained. The identification and quantification of 8-D' was assessed on GC-MS by comparison with corresponding authentic samples. In NMR spectrum, the absence signal at $6.33\left(\mathrm{H}_{\alpha}\right)$ and $6.08\left(\mathrm{H}_{\beta}\right)$ ppm indicated that $\mathrm{D}$ was well retained in product 8-D'. Own to D at $\gamma$ position retained well, the signal at $1.86 \mathrm{ppm}$ is relatively weak.
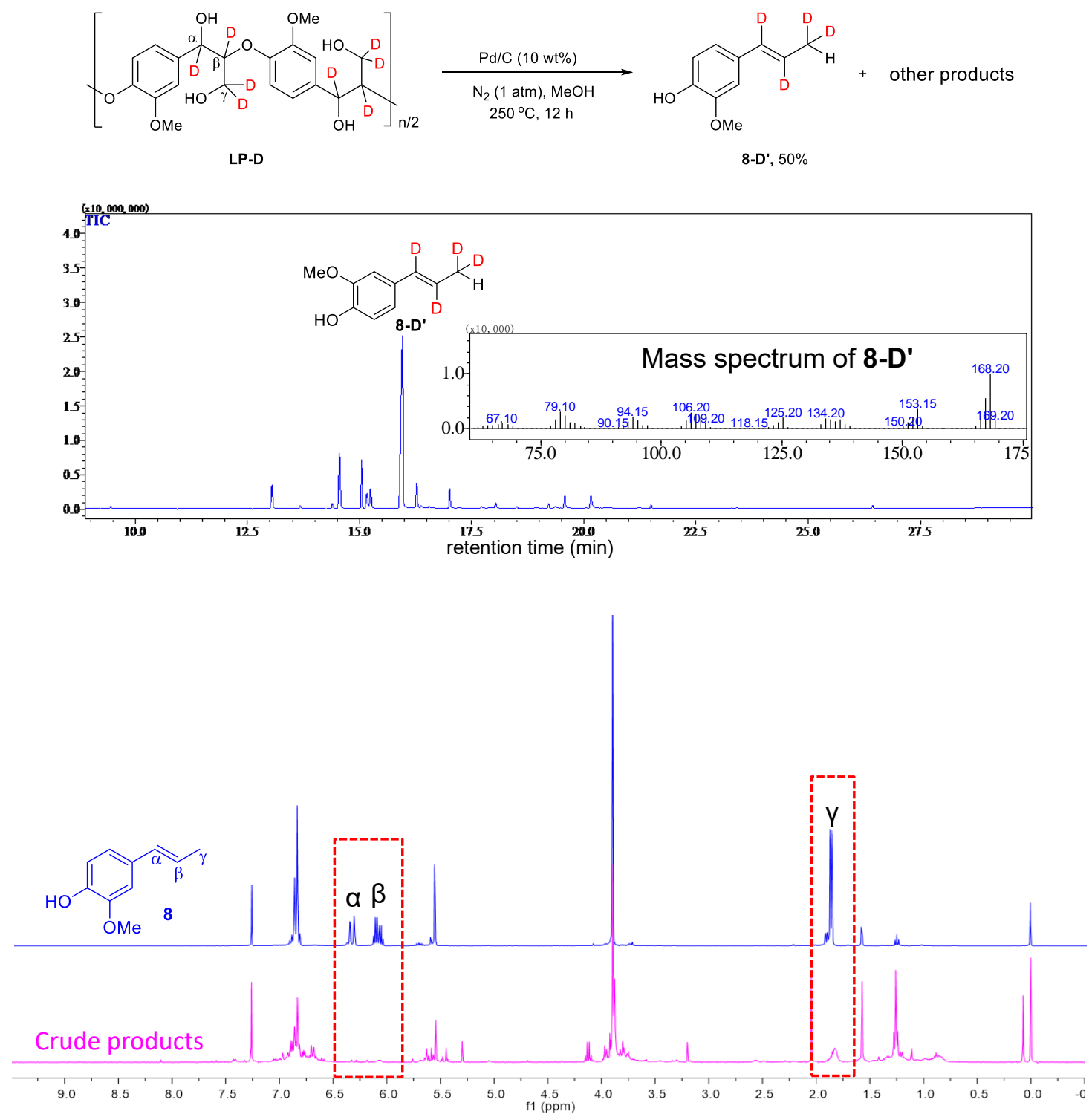

Figure S11. Characterizations of depolymerized products from hydrogenolysis of LP-D with $\mathrm{Pd} / \mathrm{C}$ under $\mathrm{H}_{2}$-free $\left(\mathrm{N}_{2}\right)$ condition. 


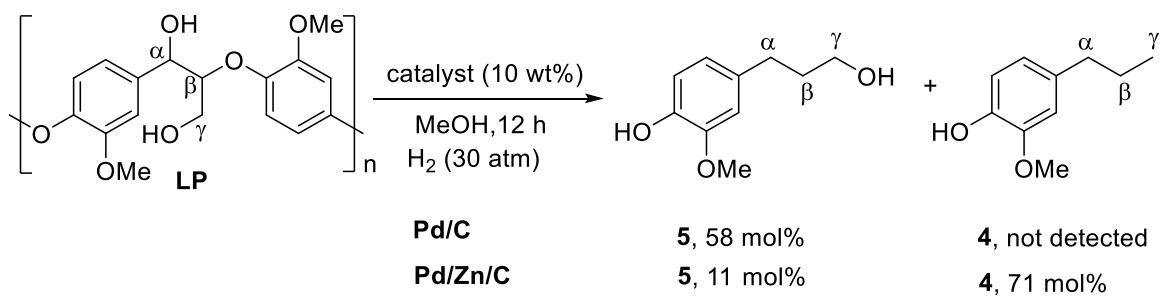

Reaction conditions: $\mathbf{L P}(60 \mathrm{mg}), \mathrm{Pd} / \mathrm{C}$ or $\mathrm{Pd} / \mathrm{Zn} / \mathrm{C}(6 \mathrm{mg}), \mathrm{MeOH}(10 \mathrm{~mL}), \mathrm{H}_{2}(30 \mathrm{~atm}), 180{ }^{\circ} \mathrm{C}$, $12 \mathrm{~h}$, in a $50 \mathrm{~mL}$ autoclave. After removal the catalyst by filtration and solvent by evaporation, the resulted oily product was dissolved in DMSO- $d_{6}$, which was then characterized by 2 D HSQC NMR spectroscopy. The signals corresponding to $\beta$-O-4 linkages (A) almost completely disappeared. The correlation signals for propanol group of 5 (labeled in blue) were observed. No cross peaks for 7 (labeled in red) could be detected. All signals were assigned based on the corresponding ${ }^{1} \mathrm{H}$ NMR and ${ }^{13} \mathrm{C}$ NMR spectra.

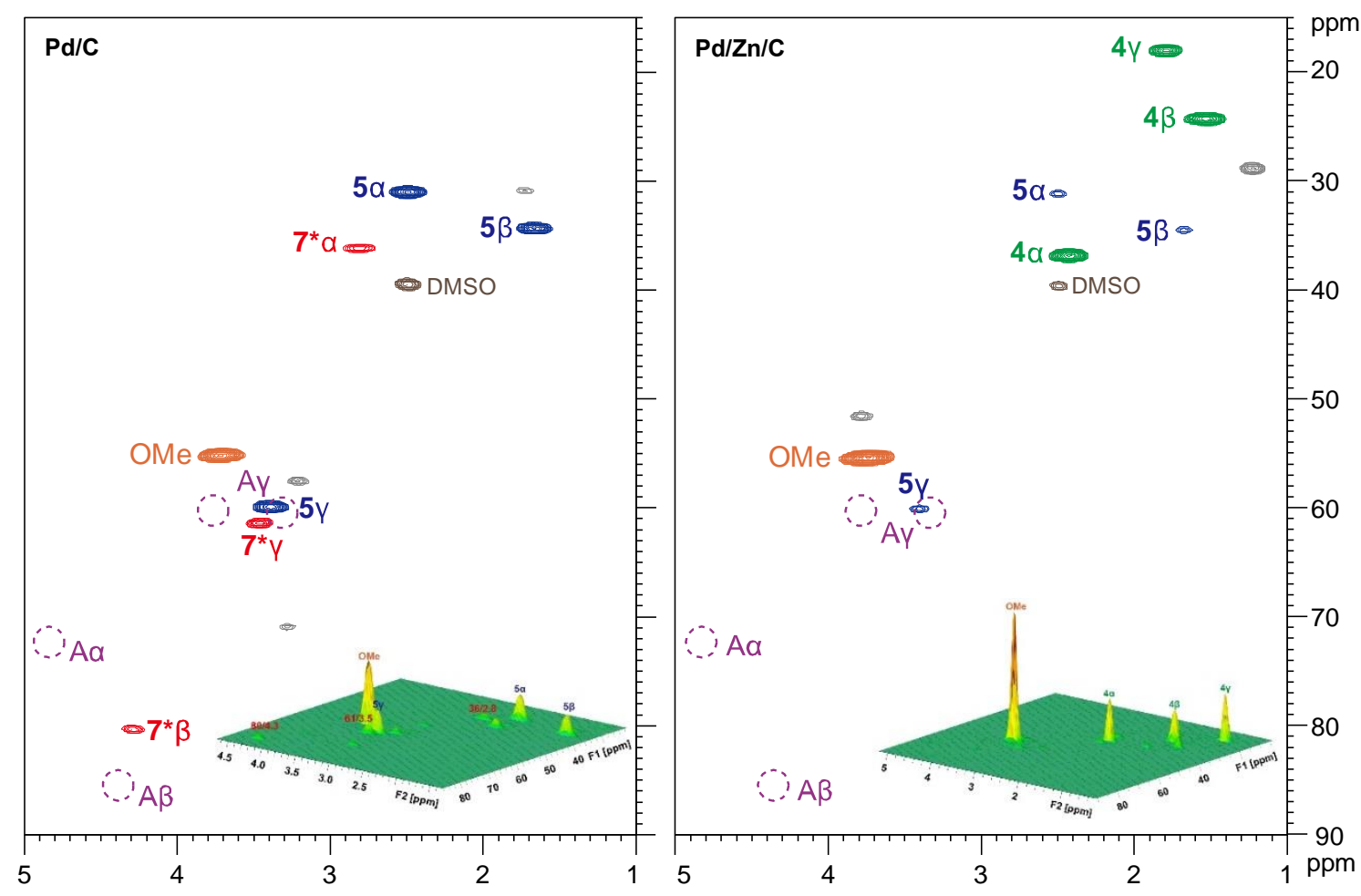




\begin{tabular}{cccc}
\hline & \multicolumn{3}{c}{${ }^{13}{ }^{1}-{ }^{1} \mathrm{H}$ cross signals $(\mathrm{ppm})$} \\
\cline { 2 - 5 } & & & \\
\hline
\end{tabular}

Figure S12. Hydrogenolysis of $\mathbf{L P}$ with $\mathrm{Pd} / \mathrm{C}$ and $\mathrm{Pd} / \mathrm{Zn} / \mathrm{C}$ at $180{ }^{\circ} \mathrm{C}$ under $\mathrm{H}_{2}$ 


\section{Pd/Zn/C catalytic system}

The catalyst $\mathrm{Pd} / \mathrm{Zn} / \mathrm{C}$ used in this part was prepared according to previous literature ${ }^{14}$, which was characterized by XRD, XPS, TEM and and XAS. For XPS characterization, $\mathrm{Pd} / \mathrm{Zn} / \mathrm{C}$ was passivated under $5 \% \mathrm{O}_{2}$ in $\mathrm{N}_{2}$ to avoid autoignition.

The TEM images showed that the Pd nanocrystallites were distributed on carbon, whereas a lattice spacing was determined as $0.233 \mathrm{~nm}$, consistent with the $\mathrm{d}$ spacing of the (110) planes of $\operatorname{Pd}(0)$. XRD patterns display typical peaks of $\operatorname{Pd}(0)$ (JCPDS No: 46-1043), where no signals ascribed to $\mathrm{Zn}$ species were observed. In XPS spectra, the characteristic peaks at $335.7 \mathrm{eV}\left(3 \mathrm{~d}_{5 / 2}\right)$ and 340.9 $\mathrm{eV}\left(3 \mathrm{~d}_{3 / 2}\right)$ were attributed to metallic $\mathrm{Pd}(0)$. (The oxidation state of $\mathrm{PdO}$ at $336.7 \mathrm{eV}$ and $342.2 \mathrm{eV}$ was observed because $\mathrm{Pd} / \mathrm{Zn} / \mathrm{C}$ was passivated before XPS characterization.). The peaks located at $1022.3 \mathrm{eV}$ and $1045.5 \mathrm{eV}$ were corresponding to $\mathrm{Zn}^{2+}$.

We also performed the XAS analysis of Pd/Zn/C. The observed Pd K-edge XANES spectra of $\mathrm{Pd} / \mathrm{Zn} / \mathrm{C}$ and $\mathrm{Pd}$ foil are quite similar, suggesting similar environments of Pd present. In EXAFS, the curve for $\mathrm{Pd} / \mathrm{Zn} / \mathrm{C}$ has a main peak around $2.75 \AA$, corresponding to the Pd-Pd scattering pair. The coordination number was estimated as 7.6, being large than that of Pd- $\mathrm{Zn}$ alloy (2.5).

These results suggested that there are no $\mathrm{Pd}-\mathrm{Zn}$ bimetallic species in current $\mathrm{Pd} / \mathrm{Zn} / \mathrm{C}$ catalyst and $\mathrm{Zn}^{2+}$ is adsorbed on carbon, being in line with the conclusion drawn by Abu-Omar. ${ }^{14}$ 
a)

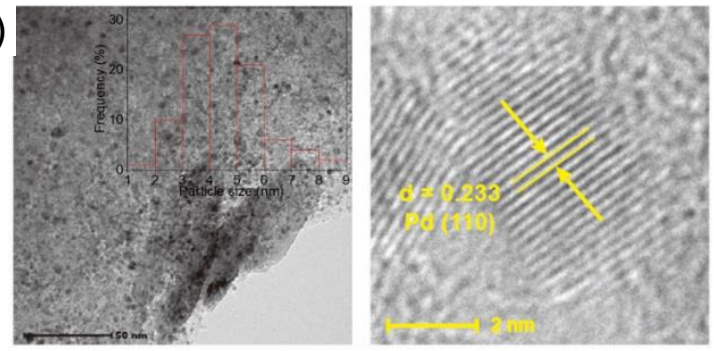

TEM

c)

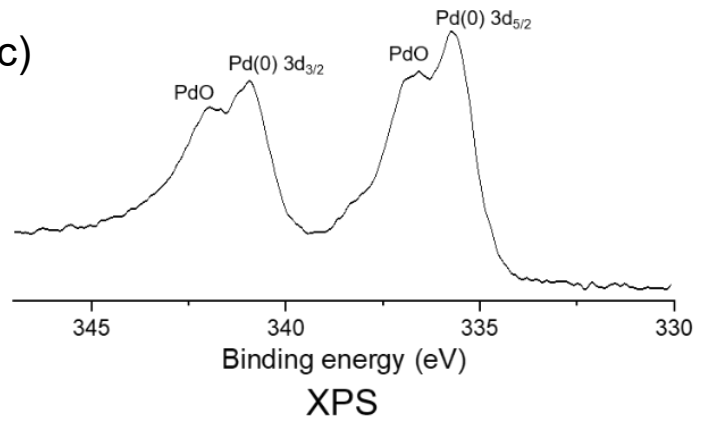

b)
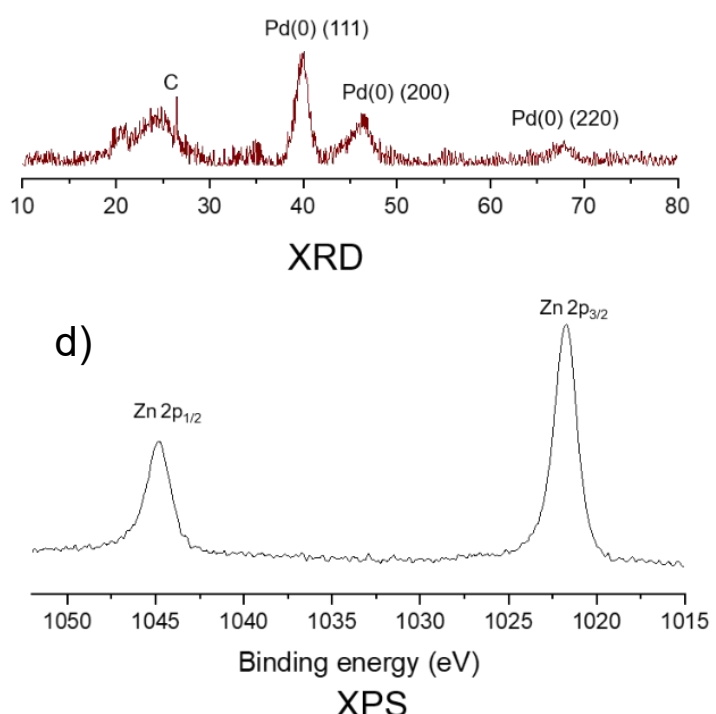

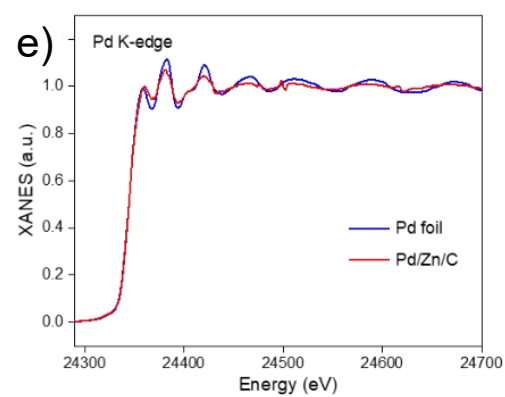

Pd K-edge XANES spectra

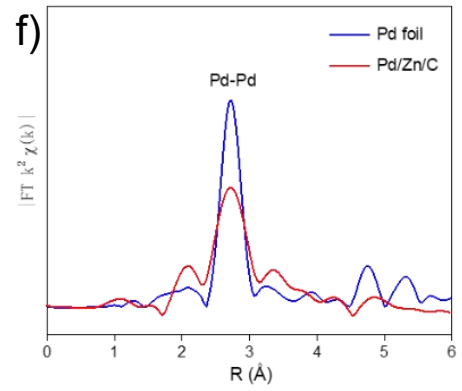

EXAFS Fourier transformed

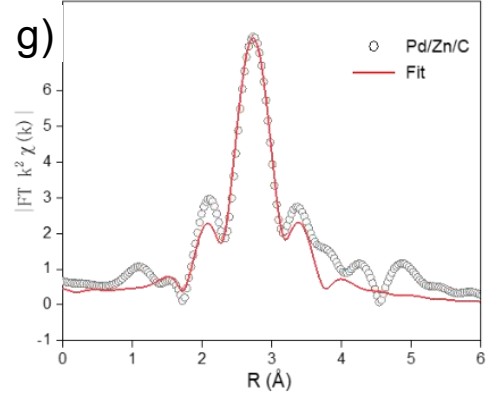

Fitting curves

(FT)

\begin{tabular}{ccccccc} 
h) Sample & $\begin{array}{c}\text { Scattering pair } \\
\text { (path) }\end{array}$ & $N$ & $\mathrm{R}(\AA \AA \mathrm{A})$ & $\sigma^{2}\left(10^{-3} \AA^{2}\right)$ & $\Delta \mathrm{E}_{0}(\mathrm{eV})$ & $\mathrm{R}$ factor \\
\hline $\mathrm{Pd} / \mathrm{Zn} / \mathrm{C}$ & $\mathrm{Pd}-\mathrm{Pd}$ & $7.6 \pm 1.7$ & $2.75 \pm 0.07$ & $8.1 \pm 0.0020$ & $-2.5 \pm 1.440$ & 0.025 \\
$\mathrm{Pd}$ foil & $\mathrm{Pd}-\mathrm{Pd}$ & $12^{*}$ & $2.74 \pm 0.08$ & $5.6 \pm 0.0001$ & $-3.0 \pm 0.294$ & 0.004
\end{tabular}

Figure S13. Characterization of the $\mathrm{Pd} / \mathrm{Zn} / \mathrm{C}$ catalyst. a) HRTEM images; b) XRD patterns; c) Pd 3d XPS spectra of passivated Pd/Zn/C; d) Zn 2p XPS spectra of passivated Pd/Zn/C; e) Pd K-edge XANES spectra; f) Fourier transformed (FT) $\mathrm{k}^{2}$-weighted $\chi(\mathrm{k})$-function of the EXAFS spectra for Pd K-edge; g) EXAFS R-space fitting curve; h) Structure parameters of $\mathrm{Pd} / \mathrm{Zn} / \mathrm{C}$ and $\mathrm{Pd}$ foil extracted from the EXAFS. 


\section{Catalytic hydrogenolysis of GG-D.}

In a $50 \mathrm{~mL}$ autoclave with a magnetic stirring bar, lignin model compound GG-D (60 mg), $\mathrm{Pd} / \mathrm{Zn} / \mathrm{C}(3 \mathrm{mg}, 5 \mathrm{wt} \%)$ and $\mathrm{MeOH}(10 \mathrm{~mL})$ were charged and sealed under $\mathrm{N}_{2}$ atmosphere, which was then evacuated and filled with $\mathrm{H}_{2}(30 \mathrm{~atm})$ at room temperature. After reaction, the autoclave was cooled to room temperature and depressurized carefully, to which tetradecane was added as a standard. The reaction mixture was filtered and the solvent was evaporated in vacuo. The obtained oily product was dissolved into $\mathrm{CH}_{2} \mathrm{Cl}_{2}$ in a $5.0 \mathrm{~mL}$ volumetric flask, which was then submitted to GC and GC-MS.

After characterization by GC-MS, the obtained mixture was purified by column chromatography on silica gel with (PE/EtOAc) to give compound 4-D and 5-D as oily products, respectively.

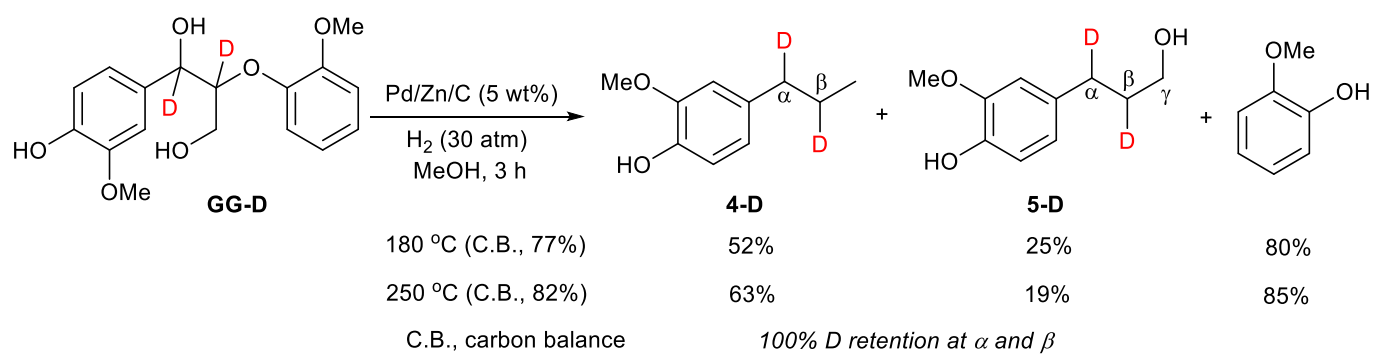

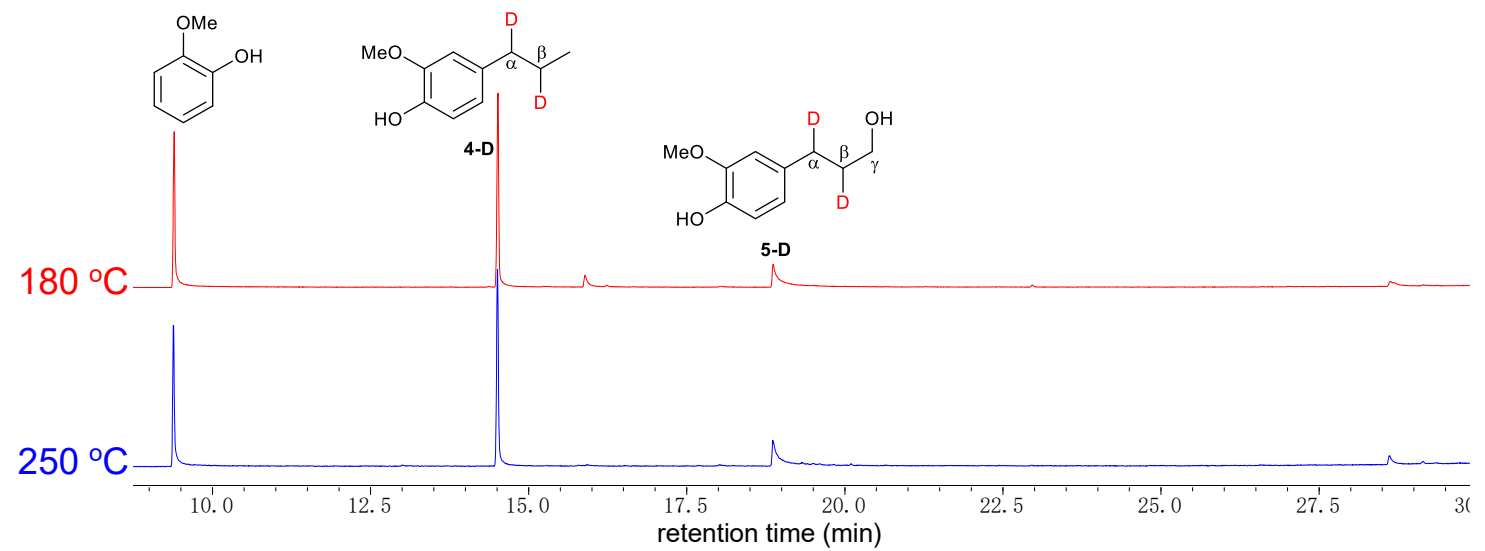



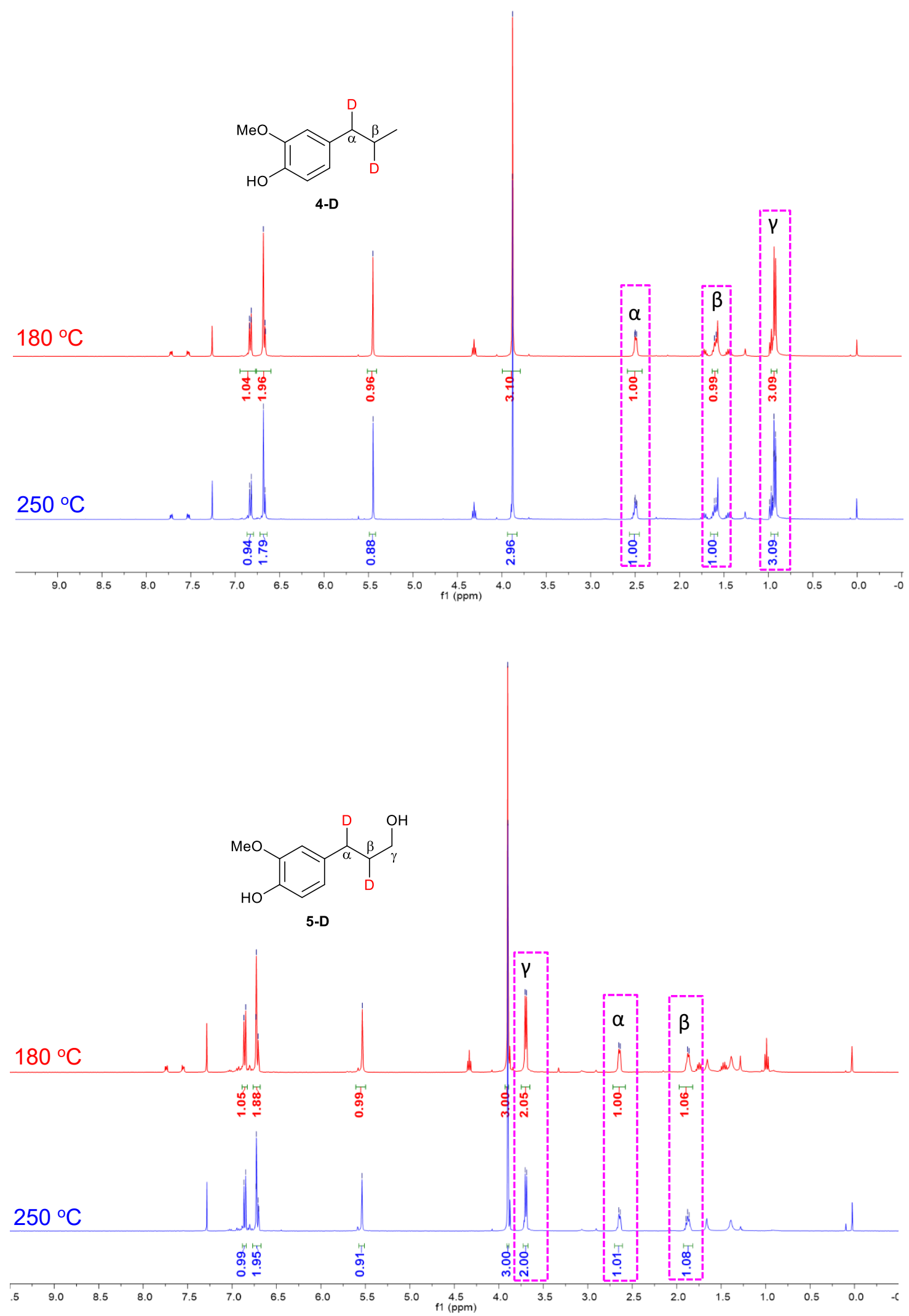

Figure S14. Characterization of depolymerized products from hydrogenolysis of GG-D with $\mathrm{Pd} / \mathrm{Zn} / \mathrm{C}$ under $\mathrm{H}_{2}$ condition. 


\section{Catalytic hydrogenolysis of LP-D}

The reaction was conducted according to the General procedure by using LP-D (60 mg) and $\mathrm{Pd} / \mathrm{Zn} / \mathrm{C}(3 \mathrm{mg}, 5 \mathrm{wt} \%)$ at $180{ }^{\circ} \mathrm{C}$ and $250{ }^{\circ} \mathrm{C}$ under $\mathrm{H}_{2}$ (30 atm at room temperature) for $12 \mathrm{~h}$. After characterization by GC-MS, the obtained mixture was purified by column chromatography on silica gel with (PE/EtOAc) to give compound 5-D as a syrup in a pure manner.
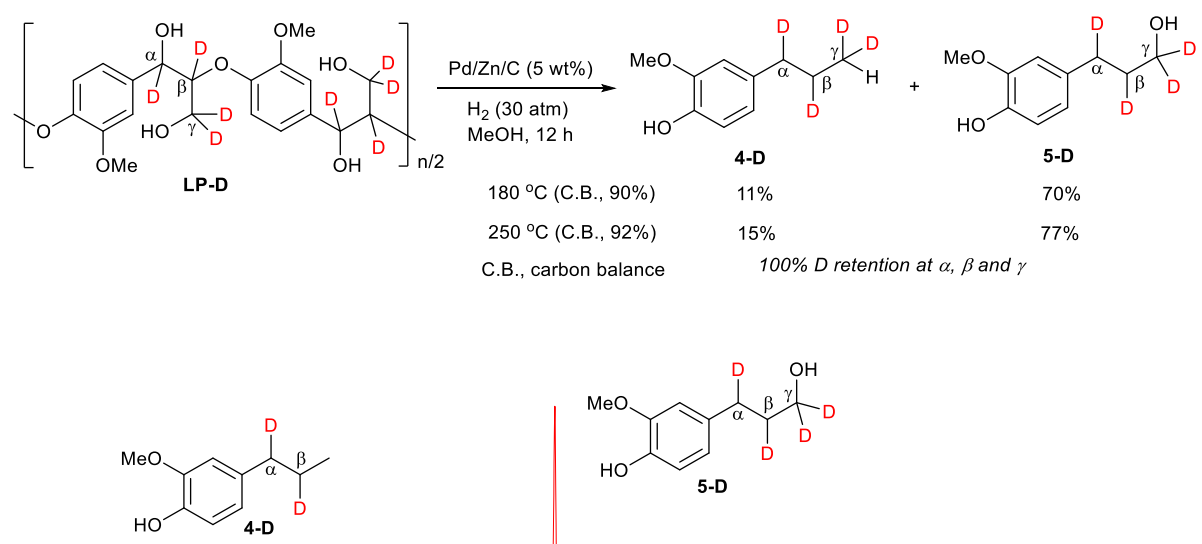

$180^{\circ} \mathrm{C}$
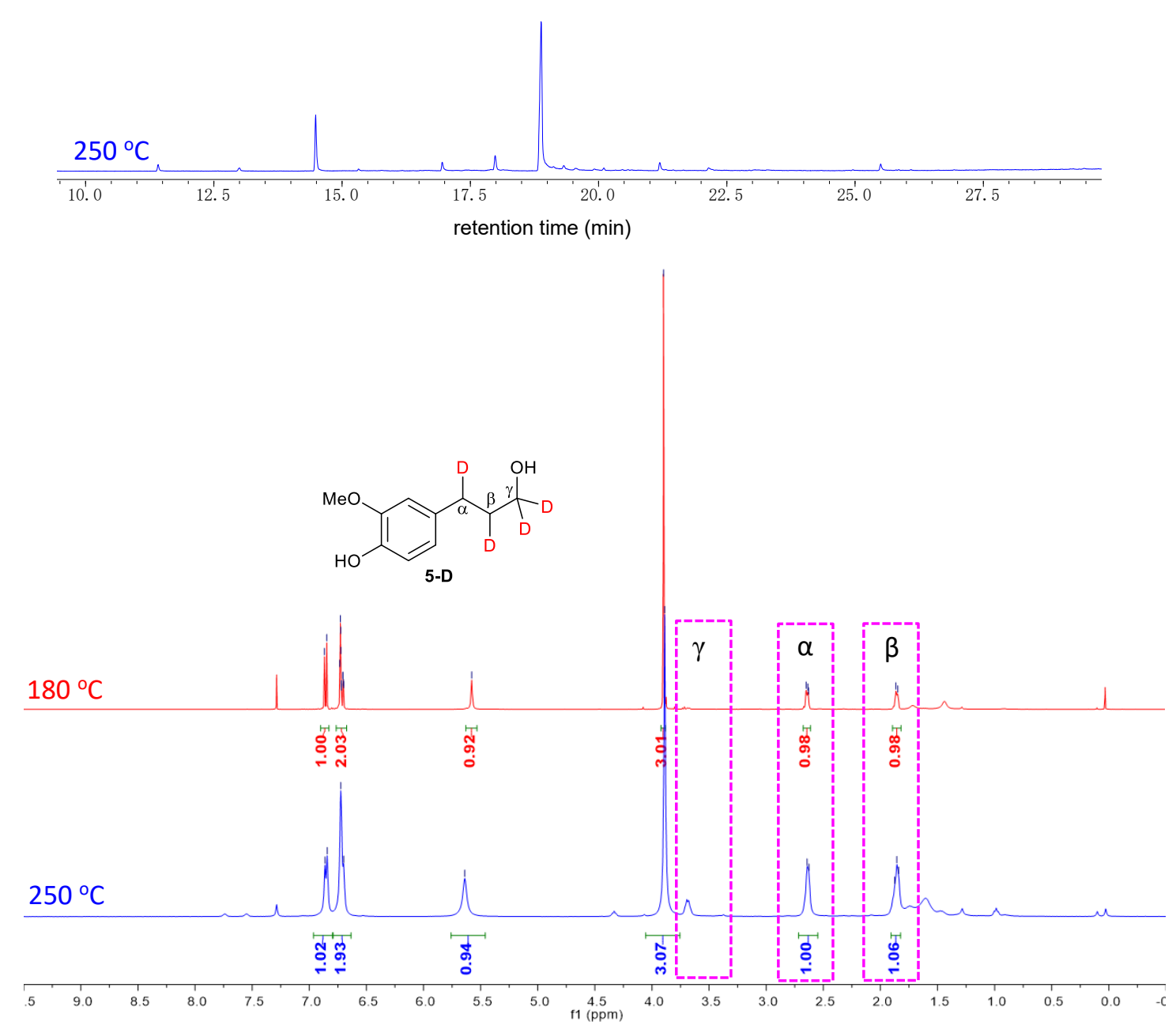

Figure S15. Characterization of depolymerized products from hydrogenolysis of LP-D with $\mathrm{Pd} / \mathrm{Zn} / \mathrm{C}$ under $\mathrm{H}_{2}$ condition. 
To obtain some information during lignin hydrogenolysis, the metal catalyst $(\mathrm{Ru} / \mathrm{C}, \mathrm{Pd} / \mathrm{C}$ and $\mathrm{Pd} / \mathrm{Zn} / \mathrm{C}$ ) was combined with GG dimer (catalyst, $100 \mathrm{mg}$; GG, $60 \mathrm{mg}$ ) in $\mathrm{MeOH}$ under $\mathrm{H}_{2}$ (30 atm). Each mixture was stirred at $25{ }^{\circ} \mathrm{C}$ and $130{ }^{\circ} \mathrm{C}$ for $3 \mathrm{~h}$, respectively. After removal of organic solvent, the solid residues were characterized directly by XRD, XPS and TEM.

No detachable changes on catalysts and treated catalysts were observed in XRD, XPS and TEM spectra.

Note: For X-ray photoelectron spectroscopy, $\mathrm{Pd} / \mathrm{Zn} / \mathrm{C}$ was passivated, so $\mathrm{PdO}$ signals were observed.

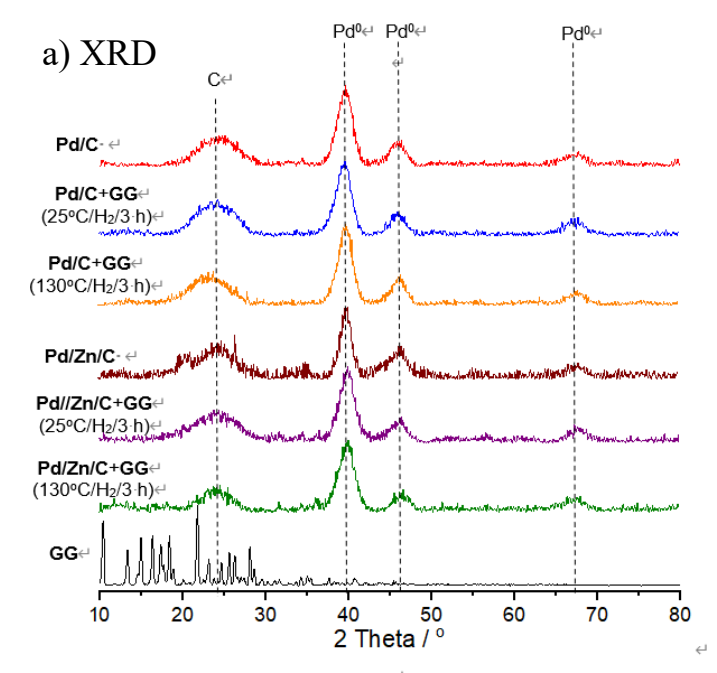
b) XPS
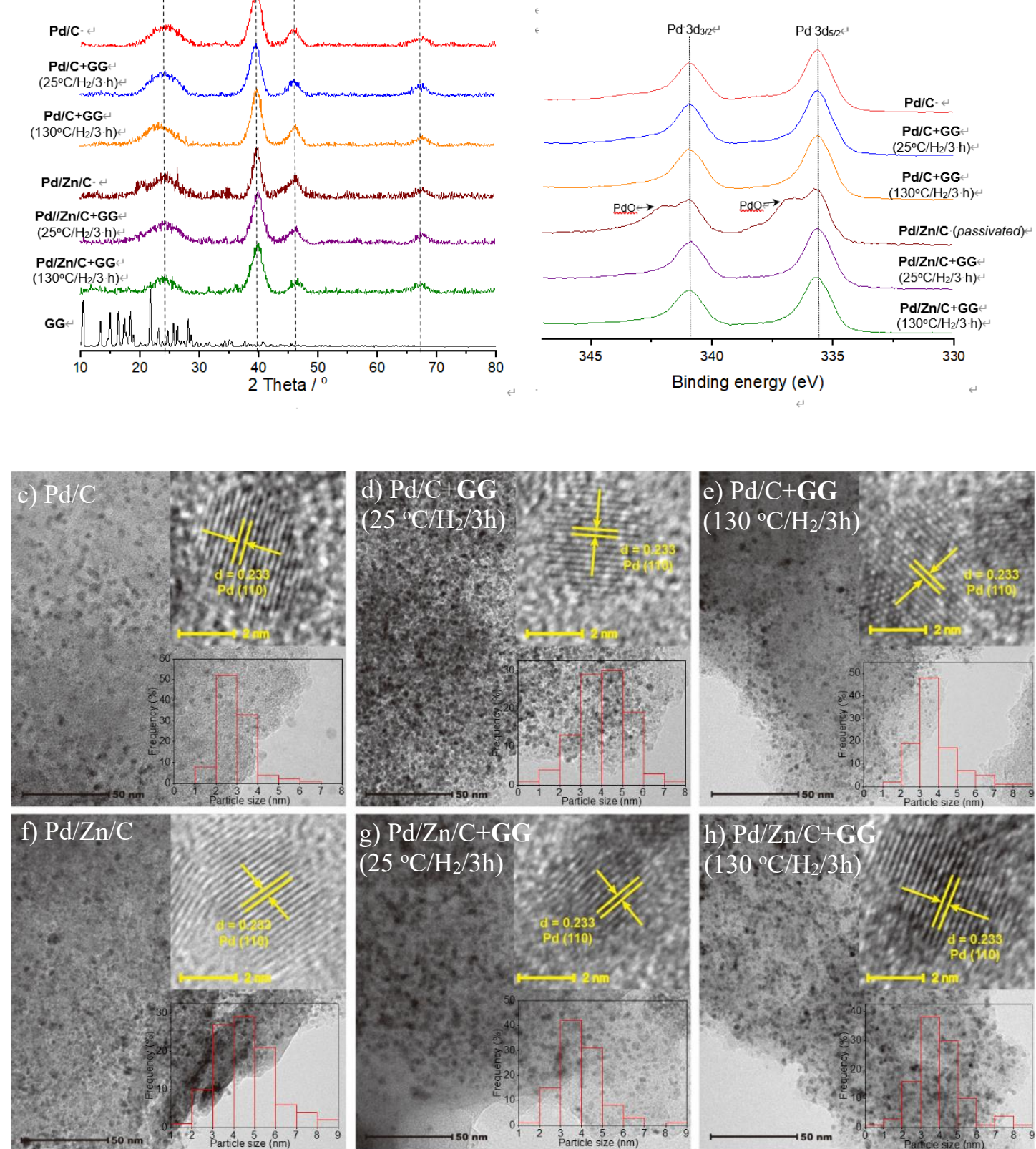

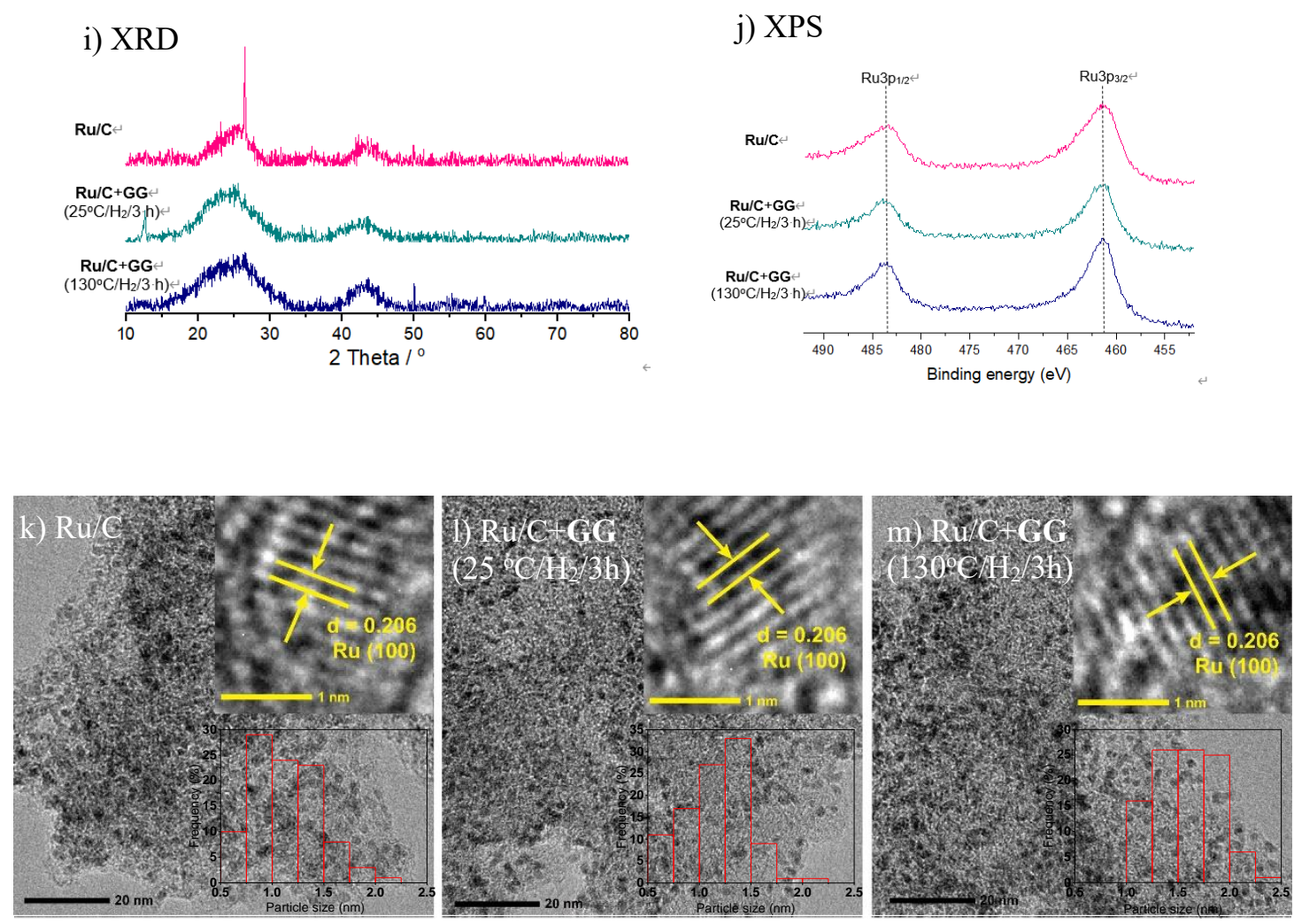

Figure S16. Characterization of the $\mathrm{Pd} / \mathrm{C}, \mathrm{Pd} / \mathrm{Zn} / \mathrm{C}$ and $\mathrm{Ru} / \mathrm{C}$ catalyst. a) $\mathrm{XRD}$ patterns of $\mathrm{Pd} / \mathrm{C}$, $\mathrm{Pd} / \mathrm{Zn} / \mathrm{C}$ and their combinations with GG; b) XPS spectra of $\mathrm{Pd} / \mathrm{C}, \mathrm{Pd} / \mathrm{Zn} / \mathrm{C}$ (passivated) and their combinations with GG; TEM images of the c) Pd/C, d) Pd/C + GG $\left(25^{\circ} \mathrm{C}, \mathrm{H}_{2}, 3 \mathrm{~h}\right)$, e) $\mathrm{Pd} / \mathrm{C}+\mathbf{G G}$ $\left.\left.\left(130{ }^{\circ} \mathrm{C}, \mathrm{H}_{2}, 3 \mathrm{~h}\right), \mathrm{f}\right) \mathrm{Pd} / \mathrm{Zn} / \mathrm{C}, \mathrm{g}\right) \mathrm{Pd} / \mathrm{Zn} / \mathrm{C}+\mathbf{G G}\left(25^{\circ} \mathrm{C}, \mathrm{H}_{2}, 3 \mathrm{~h}\right)$ and $\left.\mathrm{h}\right) \mathrm{Pd} / \mathrm{Zn} / \mathrm{C}+\mathbf{G G}\left(130^{\circ} \mathrm{C}, \mathrm{H}_{2}\right.$, 3h); i) XRD patterns of Ru/C and its combinations with GG; j) Ru 3p XPS spectra of fresh and treated $\mathrm{Ru} / \mathrm{C}$; TEM images of the $\mathrm{k}) \mathrm{Ru} / \mathrm{C}, \mathrm{l}) \mathrm{Ru} / \mathrm{C}+\mathbf{G G}\left(25^{\circ} \mathrm{C}, \mathrm{H}_{2}, 3 \mathrm{~h}\right)$ and $\left.\mathrm{m}\right) \mathrm{Ru} / \mathrm{C}+\mathbf{G G}(130$ $\left.{ }^{\circ} \mathrm{C}, \mathrm{H}_{2}, 3 \mathrm{~h}\right)$ 
NMR spectra
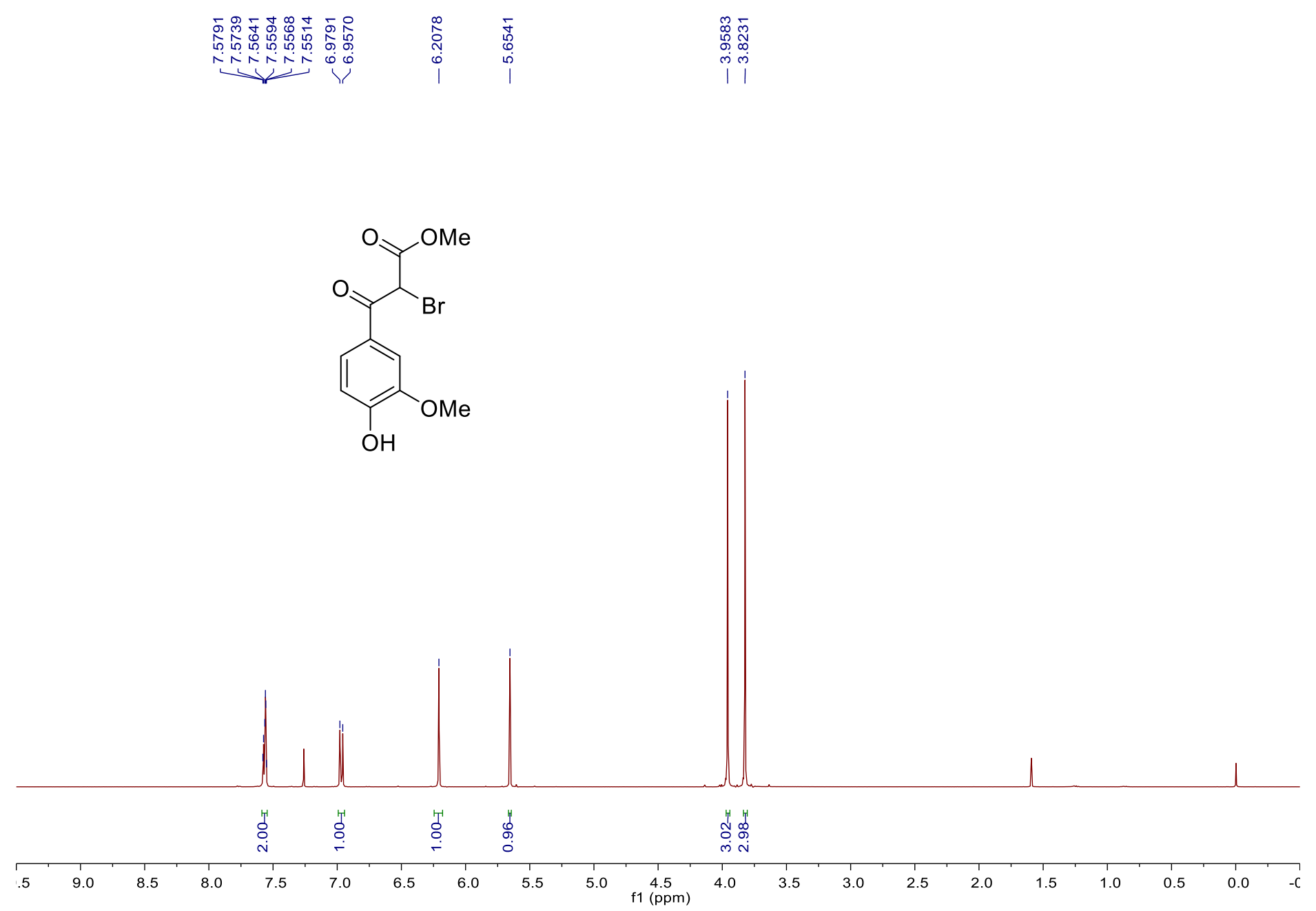


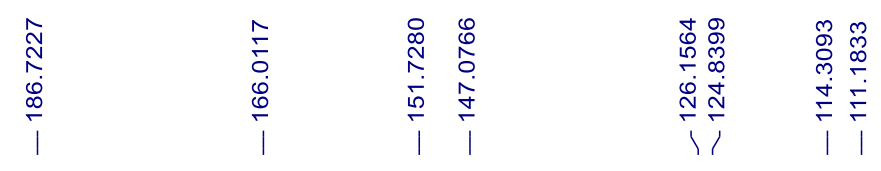

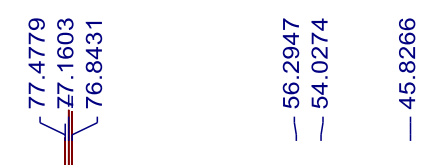

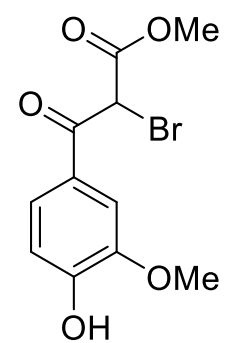

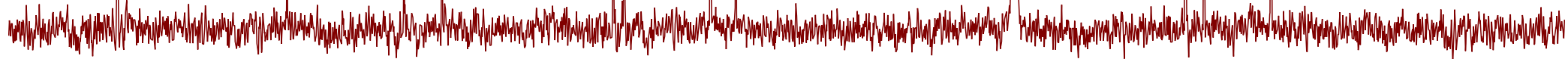

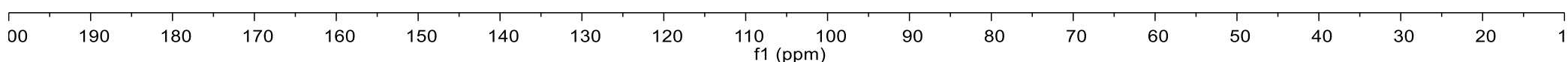



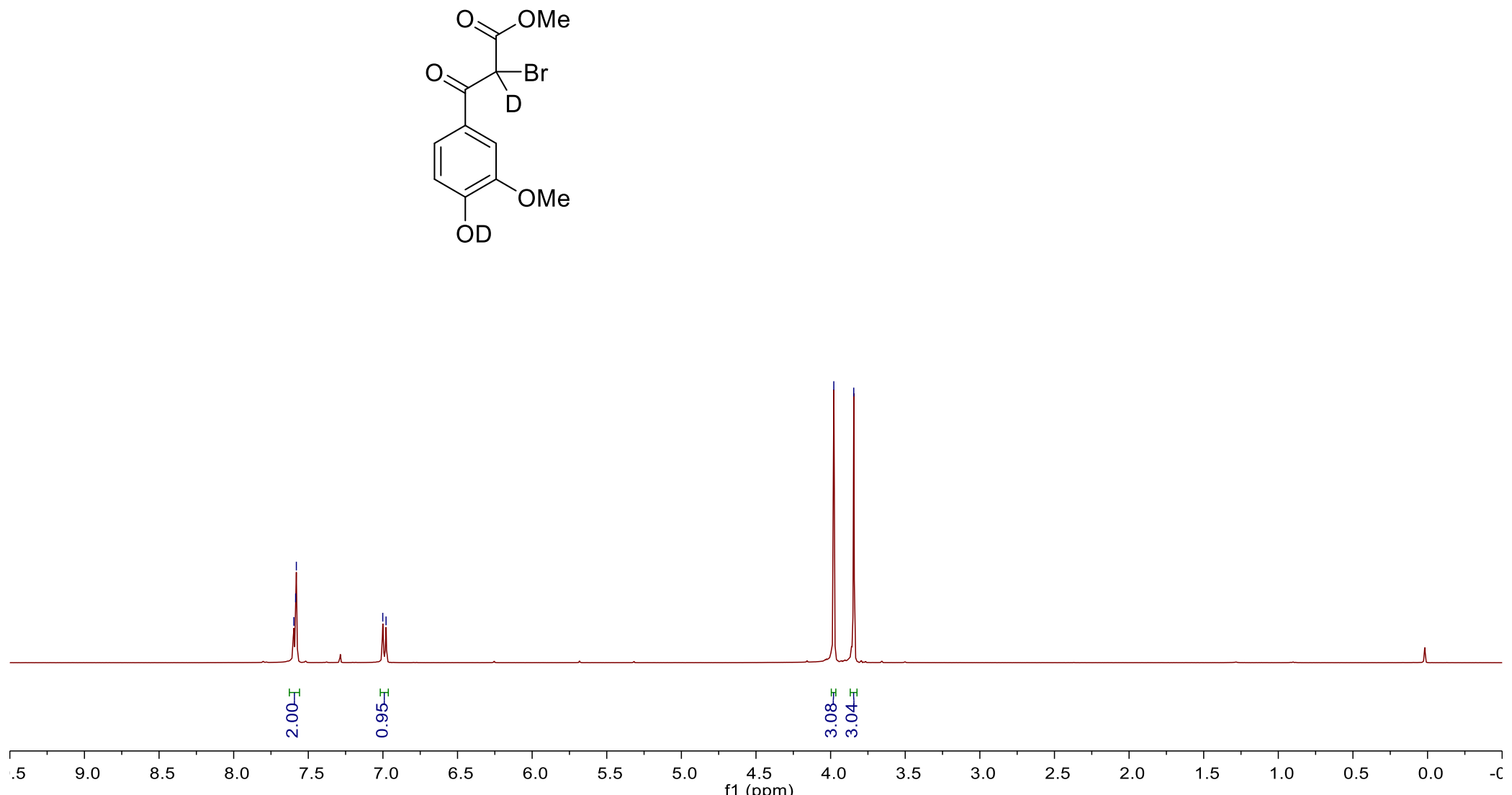


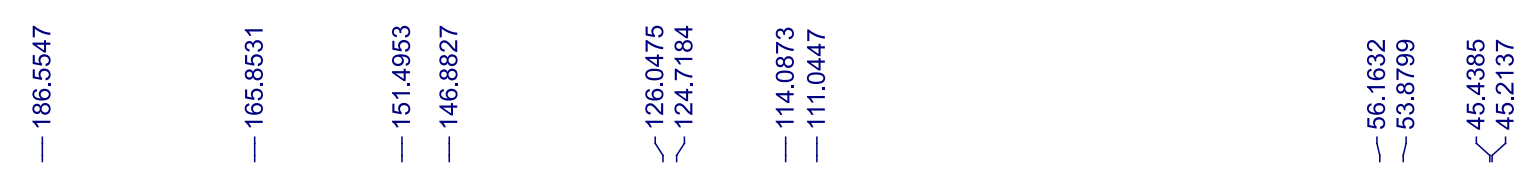

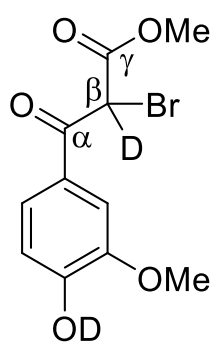

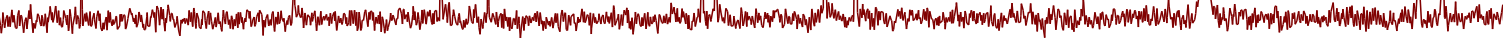

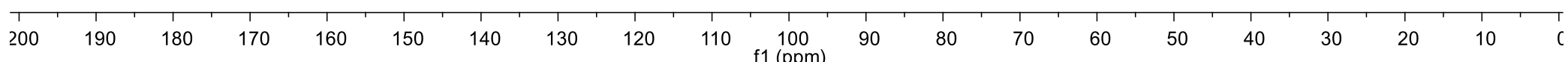


|

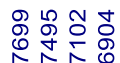

लंखिं

लir
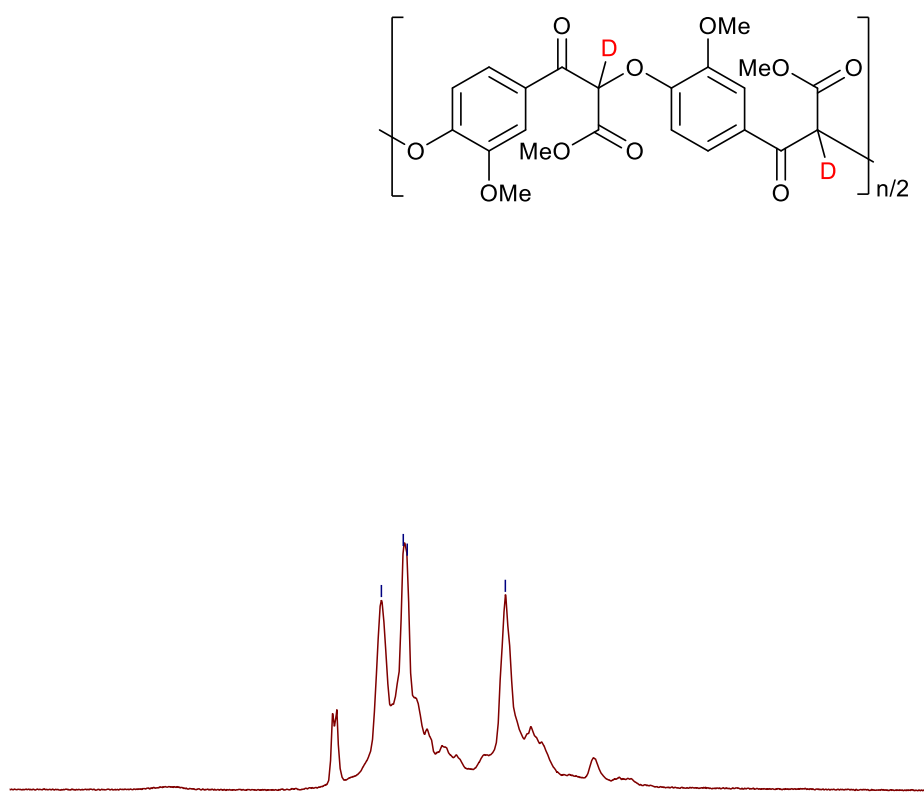

DMF

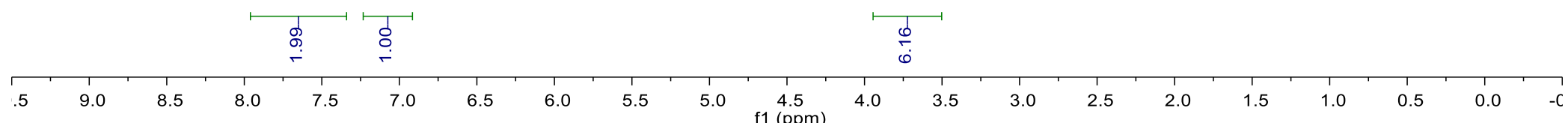




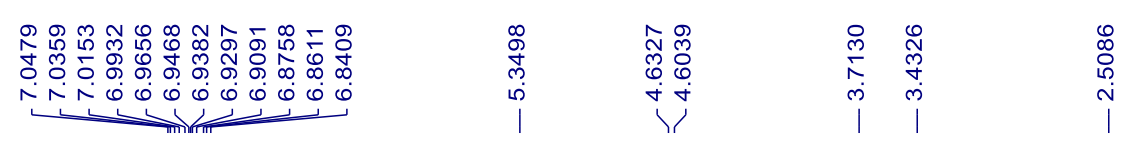

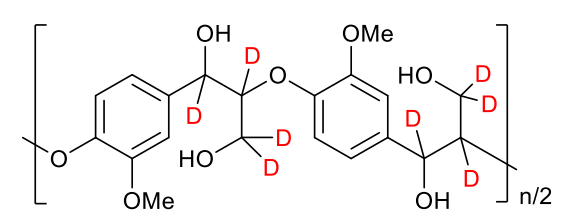

Solvent: DMSO- $d_{6}$

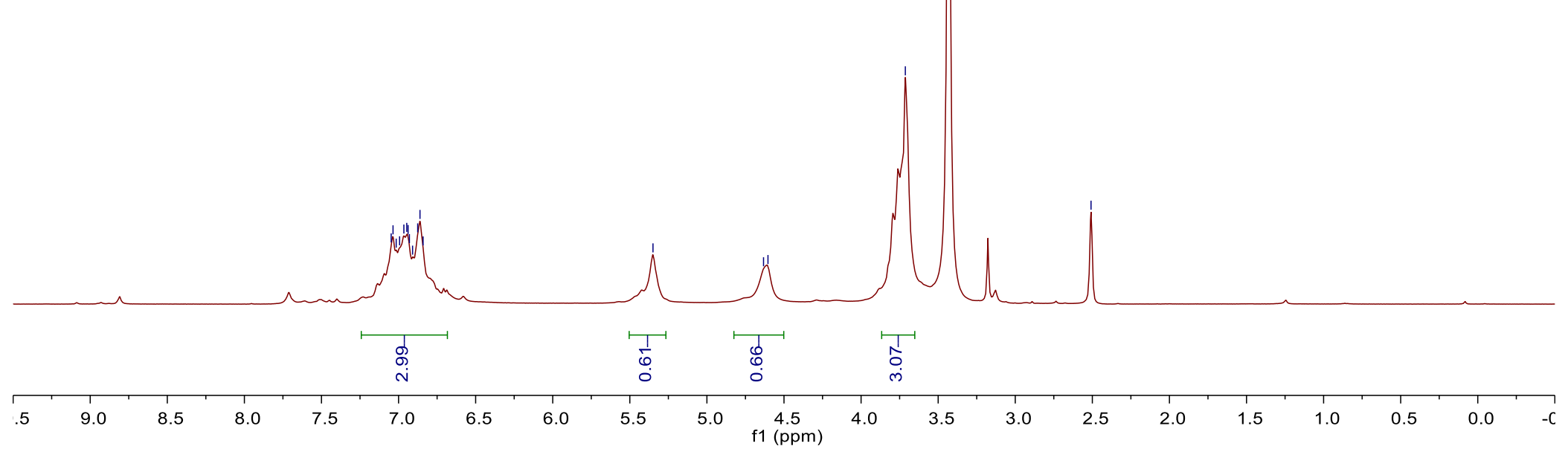




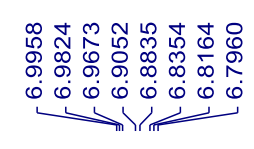

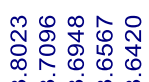

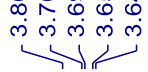

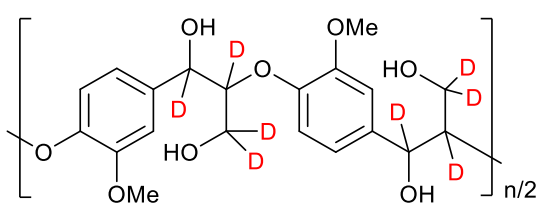

Solvent: DMSO- $d_{6}$ + one drop $\mathrm{D}_{2} \mathrm{O}$

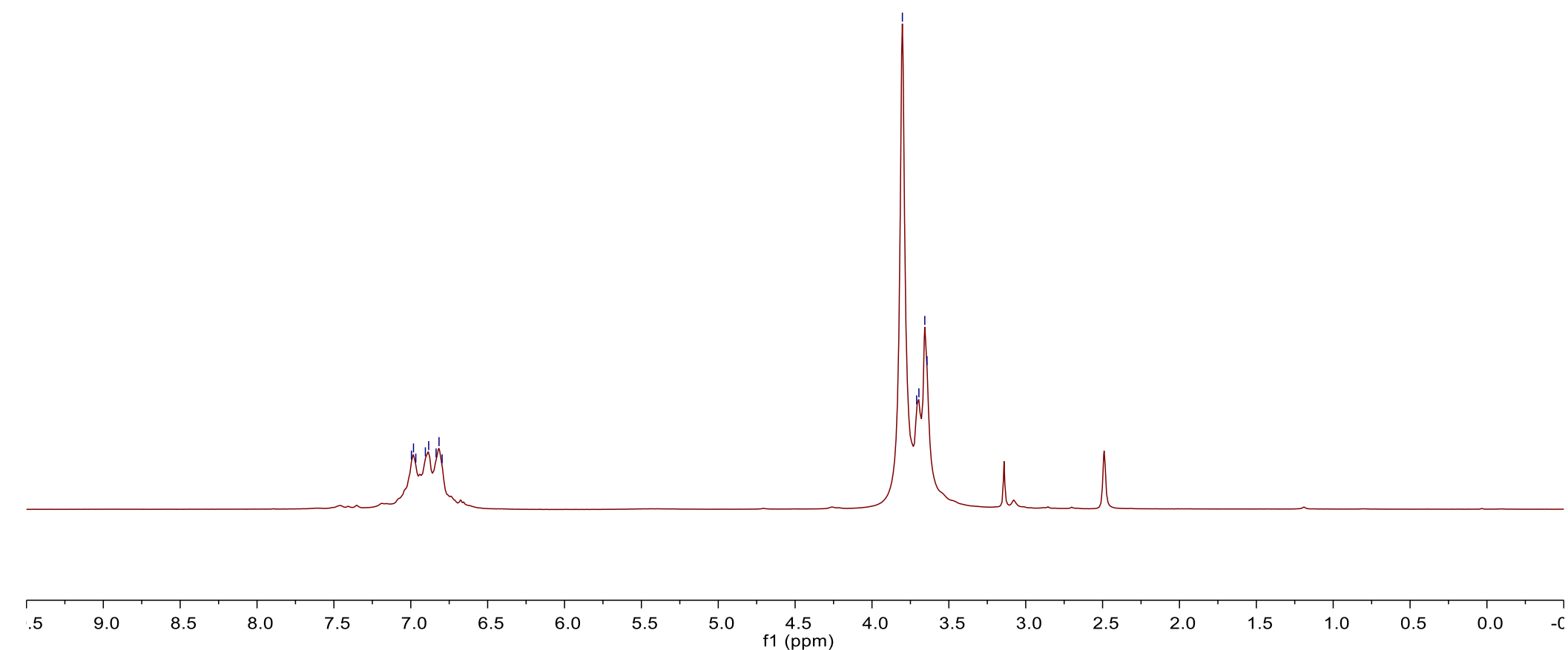




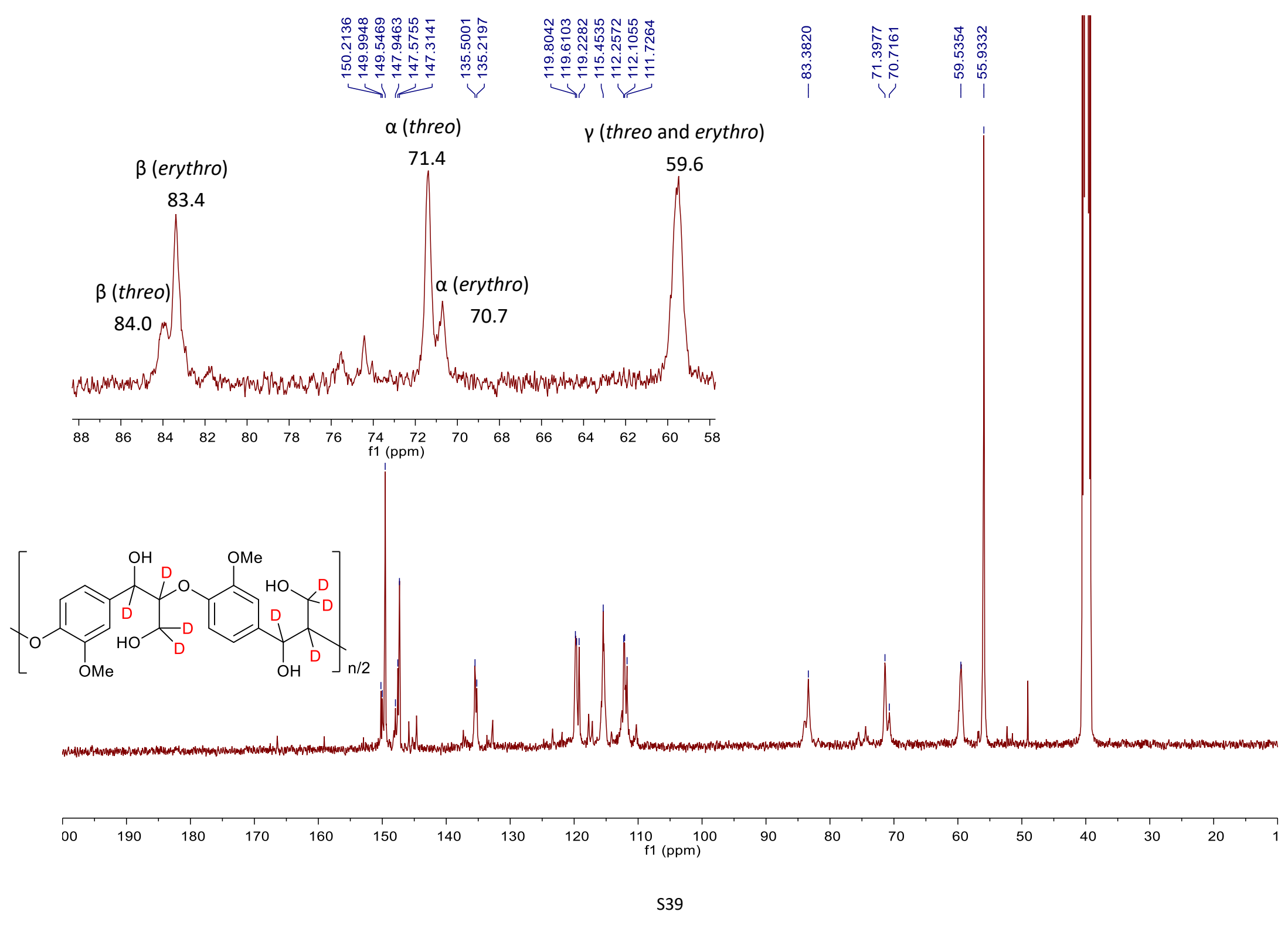




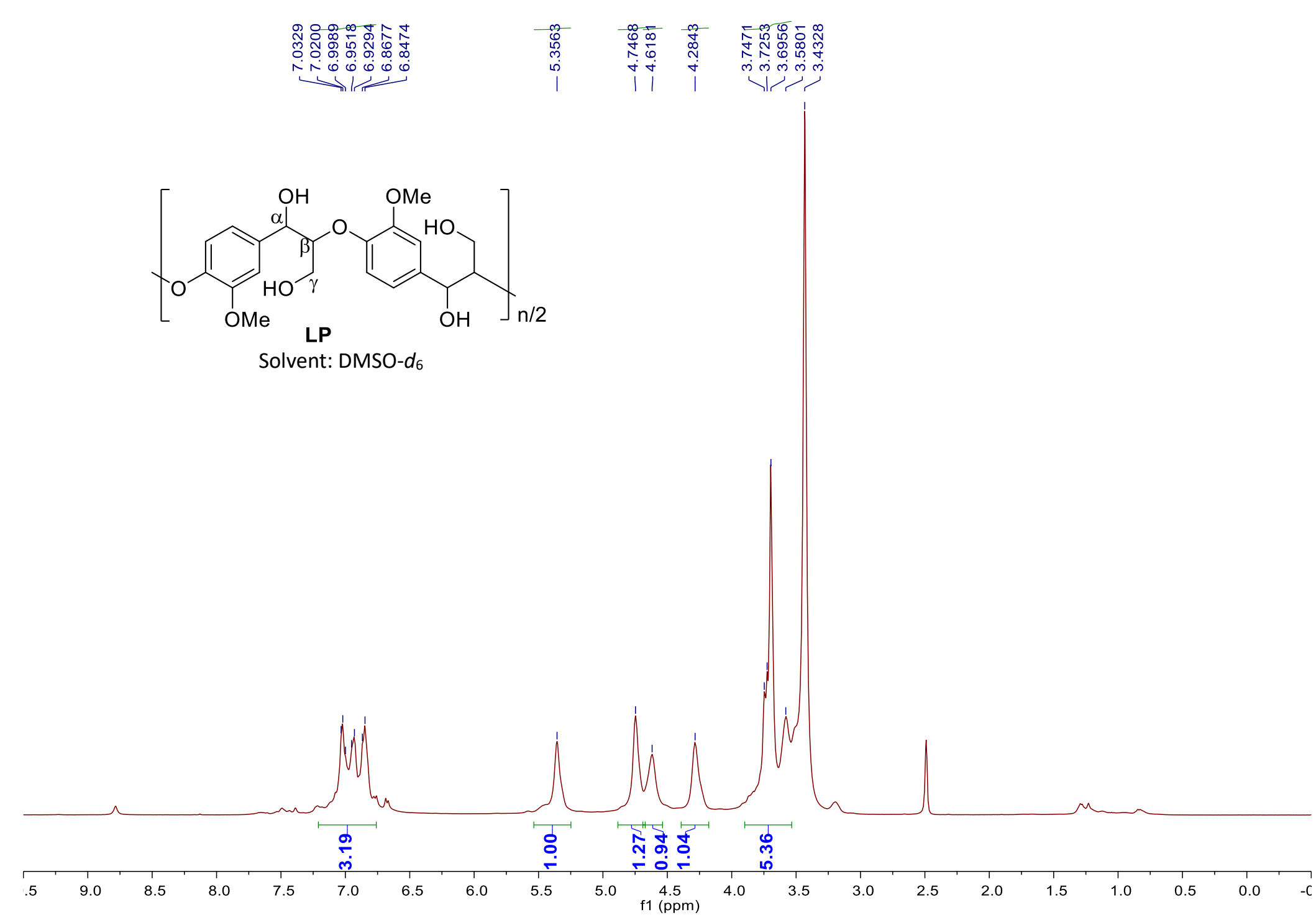




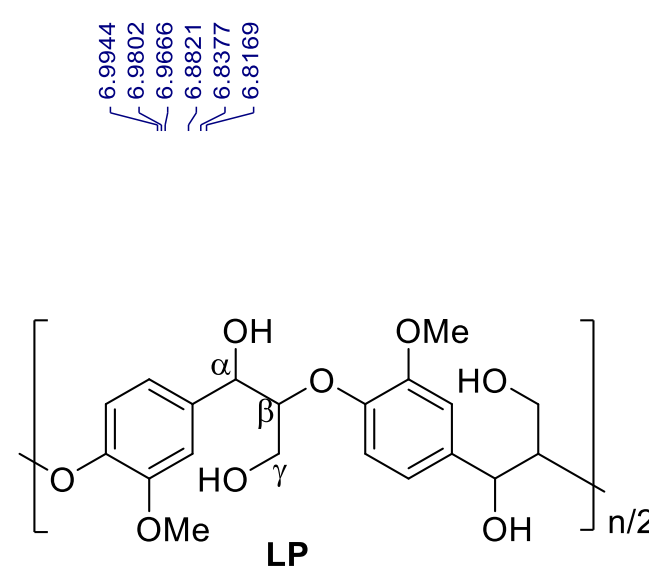

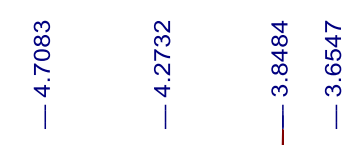

Solvent: DMSO- $d_{6}+\mathrm{D}_{2} \mathrm{O}$

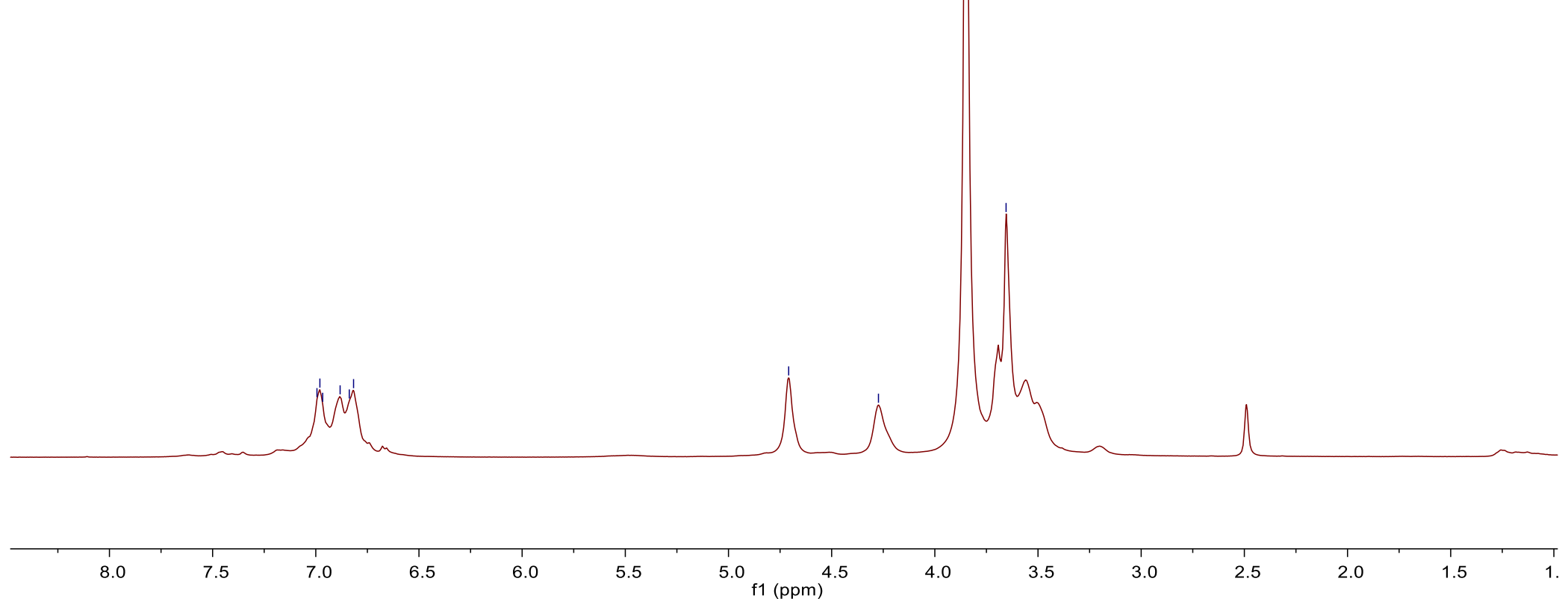

S41 

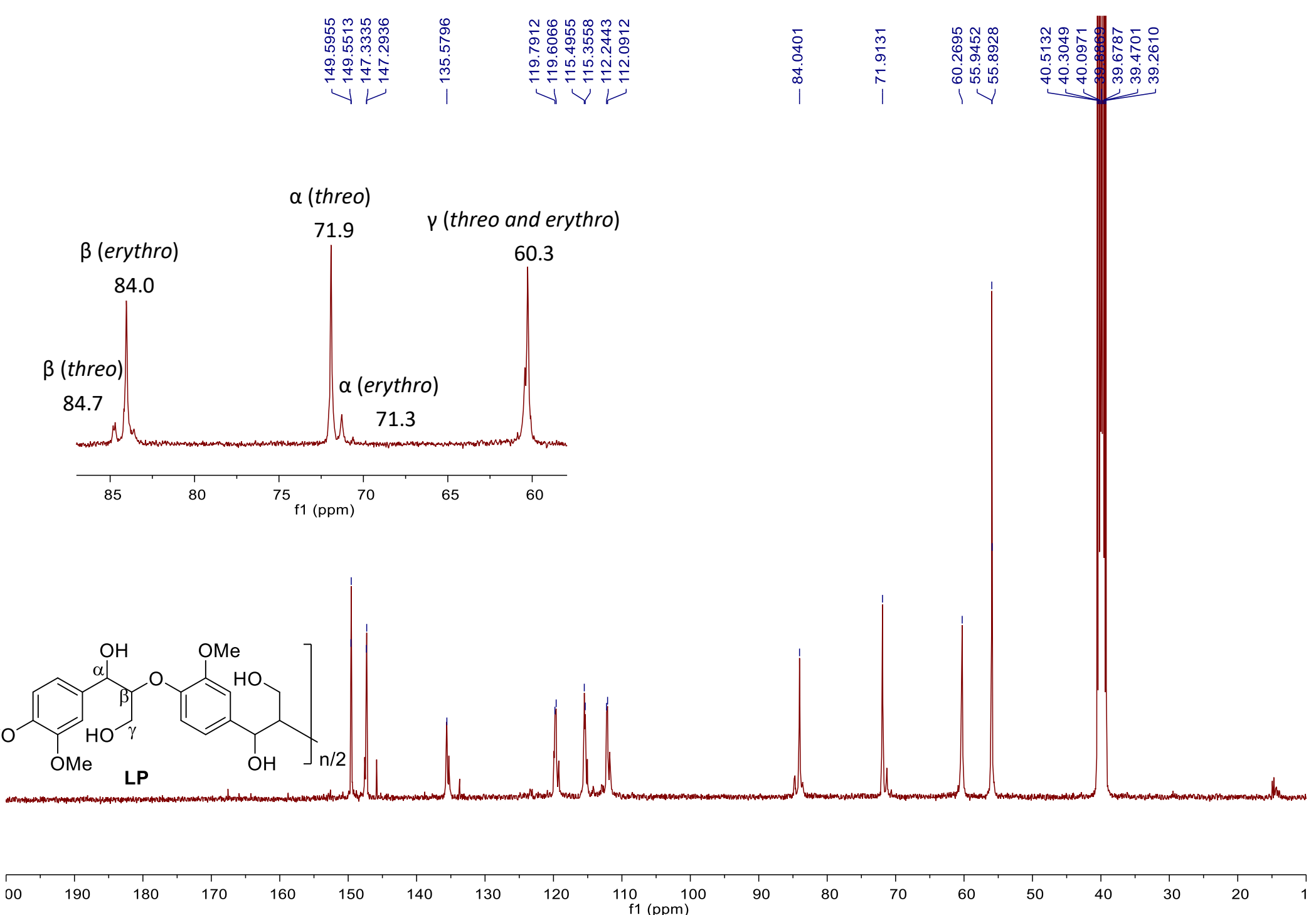

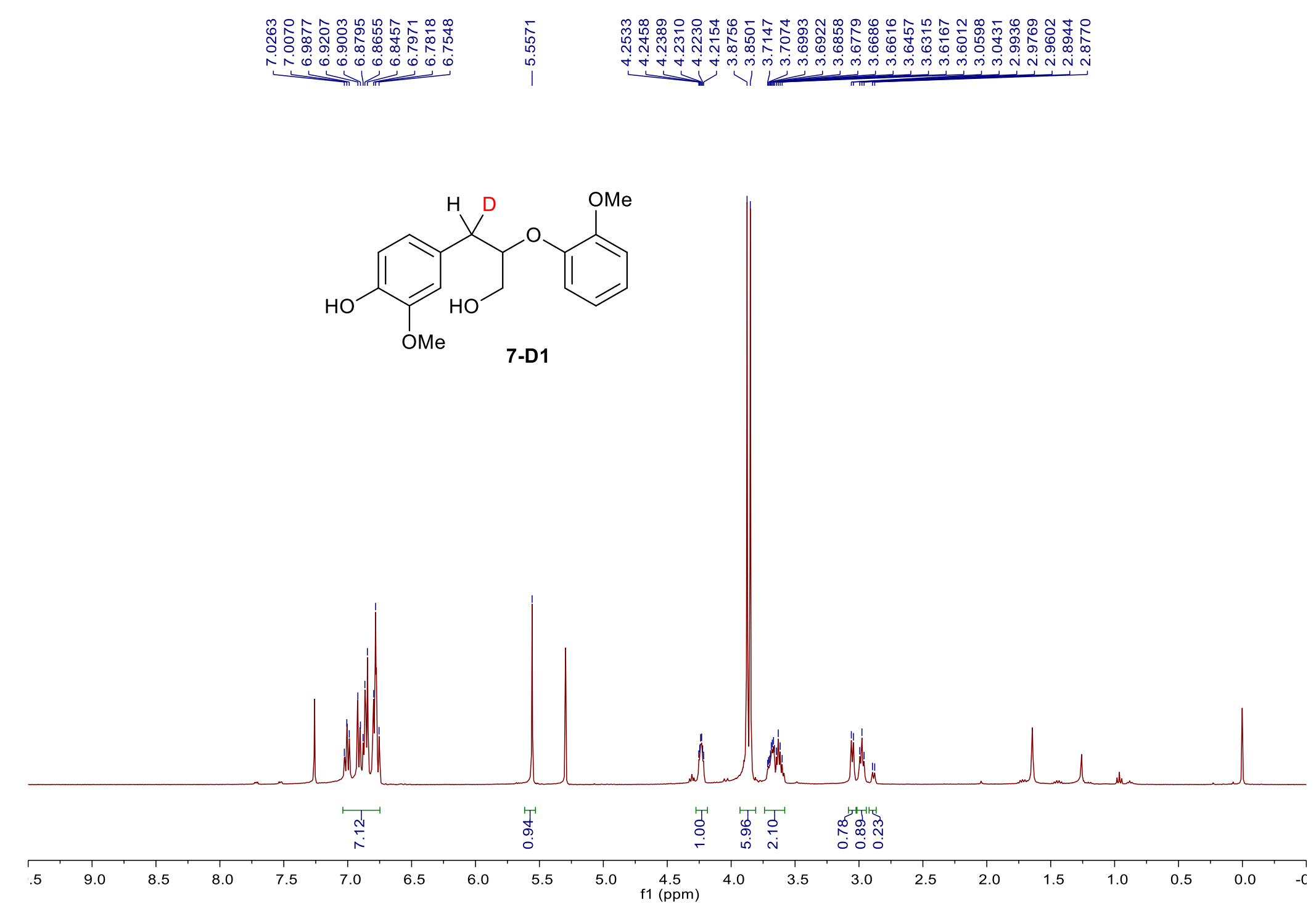

543 


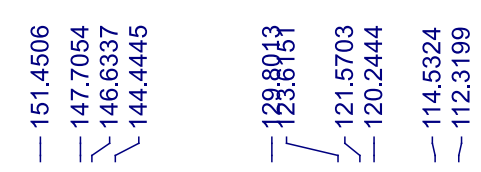

In

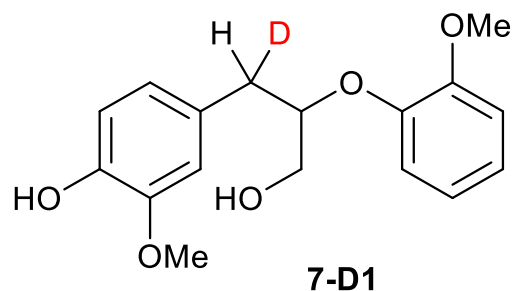

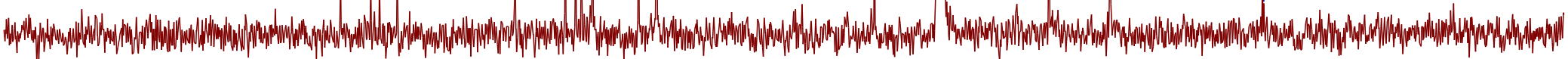

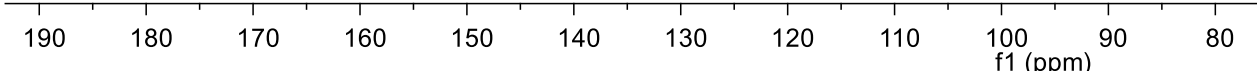




\section{References}

1. Li, H.; Song, G. Ru-Catalyzed Hydrogenolysis of Lignin: Base-Dependent Tunability of Monomeric Phenols and Mechanistic Study. ACS Catal. 2019, 9, 4054-4064.

2. Sun, Z.; Bottari, G.; Afanasenko, A.; Stuart, M. C.; Deuss, P. J.; Fridrich, B.; Barta, K. Complete Lignocellulose Conversion with Integrated Catalyst Recycling Yielding Valuable Aromatics and Fuels. Nat. Catal. 2018, 1, 82-92.

3. Nichols, J. M.; Bishop, L. M.; Bergman, R. G.; Ellman, J. A. Catalytic C - O Bond Cleavage of 2-Aryloxy-1-Arylethanols and Its Application to the Depolymerization of Lignin-Related Polymers. J. Am. Chem. Soc. 2010, 132, 12554-12555.

4. Galkin, M. V.; Smit, A. T.; Subbotina, E.; Artemenko, K. A.; Bergquist, J.; Huijgen, W. J.; Samec, J. S. Hydrogen-free catalytic fractionation of woody biomass. ChemSusChem 2016, 9, 3280-3287.

5. Lohr, T. L.; Li, Z.; Marks, T. J. Selective Ether/Ester C-O Cleavage of an Acetylated Lignin Model via Tandem Catalysis. ACS Catal. 2015, 5, 7004-7007.

6. Shuai, L.; Amiri, M. T.; Questell-Santiago, Y. M.; Héroguel, F.; Li, Y.; Kim, H.; Meilan, R.; Chapple, C.; Ralph, J.; Luterbacher, J. S. Formaldehyde Stabilization Facilitates Lignin Monomer Production During Biomass Depolymerization. Science 2016, 354, 329-333.

7. Ullah, N.; Odda, A. H.; Liang, K.; Kombo, M. A.; Sahar, S.; Ma, L.-B.; Fang, X.X.; Xu, A.-W. Metal-Acid Nanoplate-Supported Ultrafine Ru Nanoclusters for Efficient Catalytic Fractionation of Lignin into Aromatic Alcohols. Green Chem. 2019, 21, 2739-2751.

8. Klein, I.; Marcum, C.; Kenttämaa, H.; Abu-Omar, M. M. Mechanistic Investigation of the $\mathrm{Zn} / \mathrm{Pd} / \mathrm{C}$ Catalyzed Cleavage and Hydrodeoxygenation of Lignin. Green Chem. 2016, 18, 2399-2405.

9. Song, Q.; Wang, F.; Cai, J.; Wang, Y.; Zhang, J.; Yu, W.; Xu, J. Lignin Depolymerization (LDP) in Alcohol over Nickel-Based Catalysts Via a Fragmentation-Hydrogenolysis Process. Energy Environ. Sci. 2013, 6, 994-1007.

10. Sudo, K.; Mullord, D. J.; Pepper, J. M. Lignin and Related Compounds. Viii. Lignin Monomers and Dimers from Hydrogenolysis of Aspen Poplar Wood Using Rhodium-on-Charcoal Catalyst. Can. J. Chem. 1981, 59, 1028-1031.

11. Kumaniaev, I.; Subbotina, E.; Sävmarker, J.; Larhed, M.; Galkin, M. V.; Samec, J. S. Lignin Depolymerization to Monophenolic Compounds in a Flow-through System. Green Chem. 2017, 19, 5767-5771.

12. Van den Bosch, S.; Renders, T.; Kennis, S.; Koelewijn, S.-F.; Van den Bossche, G.; Vangeel, T.; Deneyer, A.; Depuydt, D.; Courtin, C.; Thevelein, J.; Schutyser, W.; Sels, B. F. Integrating Lignin Valorization and Bio-Ethanol Production: On the Role of Ni- $\mathrm{Al}_{2} \mathrm{O}_{3}$ Catalyst Pellets During Lignin-First Fractionation. Green Chem. 2017, 19, 3313-3326.

13. Kishimoto T.; Urakia Y.; Ubukata M. Chemical Synthesis of $\beta-O-4$ Type Artificial Lignin. Org. Biomol. Chem. 2006, 4, 1343-1347. 
14. Parsell, T. H.; Owen, B. C.; Klein, I.; Jarrell, T. M.; Marcum, C. L.; Haupert, L. J.; Amundson, L. M.; Kenttämaa, H. I.; Ribeiro, F.; Miller, J. T.; Abu-Omar, M. M. Cleavage and Hydrodeoxygenation (HDO) of C-O Bonds Relevant to Lignin Conversion Using Pd/Zn Synergistic Catalysis. Chem. Sci. 2013, 4, 806-813. 